\title{
A regional-scale, high resolution dynamical malaria model that accounts for population density, climate and surface hydrology
}

\author{
Adrian M Tompkins ${ }^{1 *}$ and Volker Ermert ${ }^{2}$
}

\begin{abstract}
Background: The relative roles of climate variability and population related effects in malaria transmission could be better understood if regional-scale dynamical malaria models could account for these factors.

Methods: A new dynamical community malaria model is introduced that accounts for the temperature and rainfall influences on the parasite and vector life cycles which are finely resolved in order to correctly represent the delay between the rains and the malaria season. The rainfall drives a simple but physically based representation of the surface hydrology. The model accounts for the population density in the calculation of daily biting rates.

Results: Model simulations of entomological inoculation rate and circumsporozoite protein rate compare well to data from field studies from a wide range of locations in West Africa that encompass both seasonal endemic and epidemic fringe areas. A focus on Bobo-Dioulasso shows the ability of the model to represent the differences in transmission rates between rural and peri-urban areas in addition to the seasonality of malaria. Fine spatial resolution regional integrations for Eastern Africa reproduce the malaria atlas project (MAP) spatial distribution of the parasite ratio, and integrations for West and Eastern Africa show that the model grossly reproduces the reduction in parasite ratio as a function of population density observed in a large number of field surveys, although it underestimates malaria prevalence at high densities probably due to the neglect of population migration.
\end{abstract}

Conclusions: A new dynamical community malaria model is publicly available that accounts for climate and population density to simulate malaria transmission on a regional scale. The model structure facilitates future development to incorporate migration, immunity and interventions.

\section{Background}

Models of malaria transmission are useful tools to aid understanding of the disease dynamic[1] and have long been applied to assess the potential for intervention [2-4]. As weather parameters such as temperature and precipitation are important in determining the disease niche, there is also potential, given accurate forecasts/projections of these parameters, to use malaria models that account for climate in early warning systems in epidemic regions $[5,6]$ or to assess potential shifts in niche regions under climate change scenarios [7], although in both cases incorporation of other socio-economic factors is desirable [8-10].

\footnotetext{
*Correspondence: tompkins@ictp.it

${ }^{1}$ Earth System Physics, Abdus Salam International Centre for Theoretical Physics (ICTP), Strada Costiera 11, Trieste, Italy

Full list of author information is available at the end of the article
}

As in other climate-related sectoral fields, predictive systems are often based on statistical models, which relate past case numbers to climate anomalies through regression techniques $[5,11]$. The skill of statistical models depends on the data resources available for the region of interest. Such approaches can incorporate interventions, and have increased in complexity to include random errors and relevant socio-economic indicators [12] as in a recent model developed for dengue fever in Brazil [13]. Poor, sparse or short data records confound the derivation of a reliable statistical model.

Dynamical models instead explicitly model the key equations describing the disease dynamic. A good understanding of the disease is required but if this is available this approach has the advantage of being able to incorporate day-to-day and even sub-daily diurnal variations in 
climate variables and thus differentiate transmission season risk due to sub-seasonal variability [14]. Such models can potentially be applied to different regions to those in which they were developed, although local calibration may still be required.

Early dynamical disease models used idealized equations to describe the vector and host dynamic as separate discrete compartments [2,15]. Many models have focused on the disease development within the host, with rate equations determining the passage between uninfected, infectious and recovering states and vectors given a parasite-free or infectious status. These models frequently include categories to account for immune status of the host, either to improve the model per se [16-18], or to improve our understanding of the process of immunity acquisition by determining which model best fits the available data [19-21]. Often the impact of climate was either neglected or incorporated through the force-of-infection related transmission rates.

Some recently developed dynamical models have focused on improving particular climatic aspects of the vector and parasite life-cycles. A dynamical model for the vector life-cycle has been introduced that also included a treatment of water bodies [22]. The model was designed to be run on a local scale with knowledge of the water body in question, and included the temperature sensitivity of larvae while linking water temperature to air temperature through a function of cloud cover. Another recent study also introduced a simple generic treatment of the rainfall influence on breeding sites into a dynamical model applied to single locations [23]. The Liverpool Malaria Model (LMM), which has been applied regionally to forecasting and climate projection issues $[24,25]$, includes the temperature effect on the sporogonic and gonotrophic cycles, explicitly representing the parasite and egg growth stages, as well as including a treatment of the temperature impact on vector mortality rates[26]. The model was designed to be run over a regional scale but did not include an explicit representation of the surface hydrology; egg laying rates were proportional to the 10-day rain rate. Since flushing of larvae at intense rain rates could be important in reducing malaria $[27,28]$, this relation was modified to a highly nonlinear function to account for this $[29,30]$.

While successfully applied to modelling the parasitevector cycles, one drawback of these models is that they do not explicitly represent the interaction between host and vector. The lower parasite ratio $(P R)$ values in urban areas compared to rural areas is due to a range of socio-economic factors that impact access to health facilities and treatment. Field study and survey based statistical modelling imply a reduction of entomological inoculation rate $(E I R)$ with increasing population density in peri-urban environments [31-33], indicating that surface hydrology and decreasing ratio of vector to host is key. Dynamical models that fail to incorporate host-vector dynamics may not differentiate between periurban and rural malaria. Moreover, inclusion of the host dynamic allows for an improved representation of human behaviour in malaria propagation, including interventions, treatments and also economic migration, which can reintroduce the disease into malaria-free zones [34-36].

A dynamical model has recently focused on the interaction between the host and vector, which used climate data from a single location in central Tanzania in a set of idealized simulations to investigate the impact of interventions such as bed net usage, although no comparison to data was conducted for the location [37]. Another malaria model $[38,39]$ used an agent-based approach to represent vectors and included population density. The study mapped out a rural village at a $10 \mathrm{~m}$ spatial scale, modelling growth of breeding sites using a two dimensional hydrological model and followed the evolution of each individual vector within the village domain. Such a modelling approach would be impossible to apply on a regional scale for planning purposes, due to the shear numerical cost and the lack of the detailed input required on a wide scale. While $[38,39]$ claimed that explicitly modelling each small scale breeding site of the anopheles vector and its interaction with its host was vital to present malaria transmission, we note that in the atmospheric sciences reliable weather predictions are made without explicitly modelling effects occurring below the truncation scale of the model (such as clouds and convection), but instead representing their bulk statistical effects collectively via a socalled parametrization scheme $[40,41]$. In the same way, a regional-scale malaria model can incorporate important small-scale effects such as the growth of available breeding sites (ponds and puddles) in the rainy season, representing the net bulk impact in a parametrization scheme.

The aim here is to introduce a new dynamical malaria model that can be used on a relative fine spatial resolution of order $10 \mathrm{~km}$ but applied over a regional scale and explicitly incorporates vector-host interaction in addition to a treatment of the aggregate effect of seasonal temporary bodies in a pond model. While idealized, the hydrological component puts a framework into place that will allow future development such as incorporating landsurface related permanent breeding sites and coupling to a more complex surface hydrology. Moreover, the inclusion of the population density will facilitate the future study of such phenomena as host migration, interventions and urbanization. Thus the model presented here provides a tool that takes a first step towards fulfilling two of the recommendations of [42]: to understand the relationships between climate and climate-sensitive diseases and health issues under different environmental conditions by incorporating other data into ... health forecast 
services, for example population, rural vs. urban residence, [and] migration. After introducing the model framework, an evaluation the model is conducted in an idealized framework and also using point and gridded regional integrations comparing the model to field studies of entomological parameters, malaria atlas project (MAP) processed survey data and an existing dynamical model. This evaluation demonstrates the ability of model to predict the seasonality and spatial distribution of malaria transmission, before the future directions are summarized.

\section{Methods}

\section{Overview of the VECTRI model}

The malaria model presented is a grid cell distributed dynamical model and is referred to as VECTRI; the vectorborne disease community model of the International Centre for Theoretical Physics, Trieste. This manuscript documents VECTRI release version v1.25 as of June 2012. In as far as possible, the model physics and associated parameters are taken from the literature for the Anopheles gambiae complex and the Plasmodium falciparum malaria parasite. In the present version each location (grid cell) is independent, but the structure of the model will allow communication between grid cells such as vector flight or human population migration to be easily incorporated. The following sections describe the basic structure of the model, with emphasis placed on its novel aspects.

Since one goal of the model is its successful application regionally to forecast epidemic outbreaks in malaria marginal zones in addition to representing malaria transmission in endemic regions, it is important to represent the delay between the rainy season onset and the malaria season. Thus the model explicitly resolves the growth stages of the egg-larvae-pupa cycle in addition to the gonotrophic and the sporogonic cycles using an array of bins for each process, similar to the LMM. The structure of the model is depicted schematically in Figure 1. It shows the division of the larvae life cycle $(L)$ into a number $\left(N_{L}\right)$ of discrete fractional bins $(i)$. The real number stored in each bin, $L_{i}$, gives the larvae density (per square metre) at a particular fractional growth stage $f$ (where $f$ ranges from 0 to 1 ). Oviposition results in eggs added to the first bin and each timestep of the model larvae advance a number of bins at a fractional growth rate $R_{L}$ (units $s^{-1}$ ), depending on the local water temperature, until they reach the final bin $L_{N_{L}}$ (representing $f=1$ ) and develop into adult mosquitoes. The equations solved are thus the classic advection equation:

$$
\frac{d L}{d t}=R_{L} \frac{d L}{d f} .
$$

The vector status is also bin resolved, consisting of two properties: the gonotrophic and sporogonic cycles. It is thus represented as a two dimensional array
$V\left(N_{\text {gono }}, N_{\text {sporo }}\right)$. All vectors in the first gonotrophic bin $\sum_{j=1}^{N_{\text {sporo }}} V(1, j)$ are in meal-searching mode, and once a meal is obtained, the vectors advance in terms of the egg development state at a rate $R_{V, \text { gono }}$ related to ambient temperature until the final bin is reached (using the advection equation similar to eqn. 1). At this point the vector lays a new raft of eggs and is recycled to the first meal-searching bin.

Each timestep, parasite transmission may occur to a proportion of the biting vectors, and the status of these vectors will subsequently additionally progress in the sporogonic dimension, with the rate $R_{V \text {,sporo }}$ again determined by temperature. Once vectors reach the final bin they are infective to humans and remain so until death. A third array of bins maps the status of the disease in the human host $(H)$ population (dimension $N_{H}$ ), with the first bin representing the uninfected population. The model does not include age or immunity factors, which is the subject of present model development.

Thus, while the model introduces new relationships regarding the surface hydrology and the explicit interaction between vector and host, the underlying numerical structure is similar to that employed in the LMM [26]. A timestep of one day is used to integrate the model equations, although a shorter timestep could be used if input data (temperature/rainfall) are available on these timescales, and the advection equation is solved using a simple upstream numerical scheme.

The model can be flexibly integrated using a wide range of horizontal resolutions. Since the model presently does not permit vectors to move to neighbouring grid cells, the model resolution is limited to an upper (finest) level on the order of 1-5 km; an indicated range below which mosquito movement can become significant [43-45]. Integrating the model at $\mathrm{O}(10 \mathrm{~km})$ resolution is desirable, even if corresponding observational data of clinically proven malaria cases is available only on coarser scale health districts. This is because malaria transmission is a highly nonlinear function of its drivers such as climate and land surface and thus it is preferable to use highest possible spatial resolution inputs of population density, land surface and weather to account for this, while the model output is subsequently aggregated to the spatial scale at which health data is available for comparison.

\section{Structure of the VECTRI model}

The following section describes the details of the parametrizations used to describe the temperaturesensitive progression rates and details the new developments in the VECTRI model concerning the representation of the human population density, which impacts the biting rates, and the treatment of surface hydrology which determines the overall vector number. To enable VECTRI to be used in a multi-model 


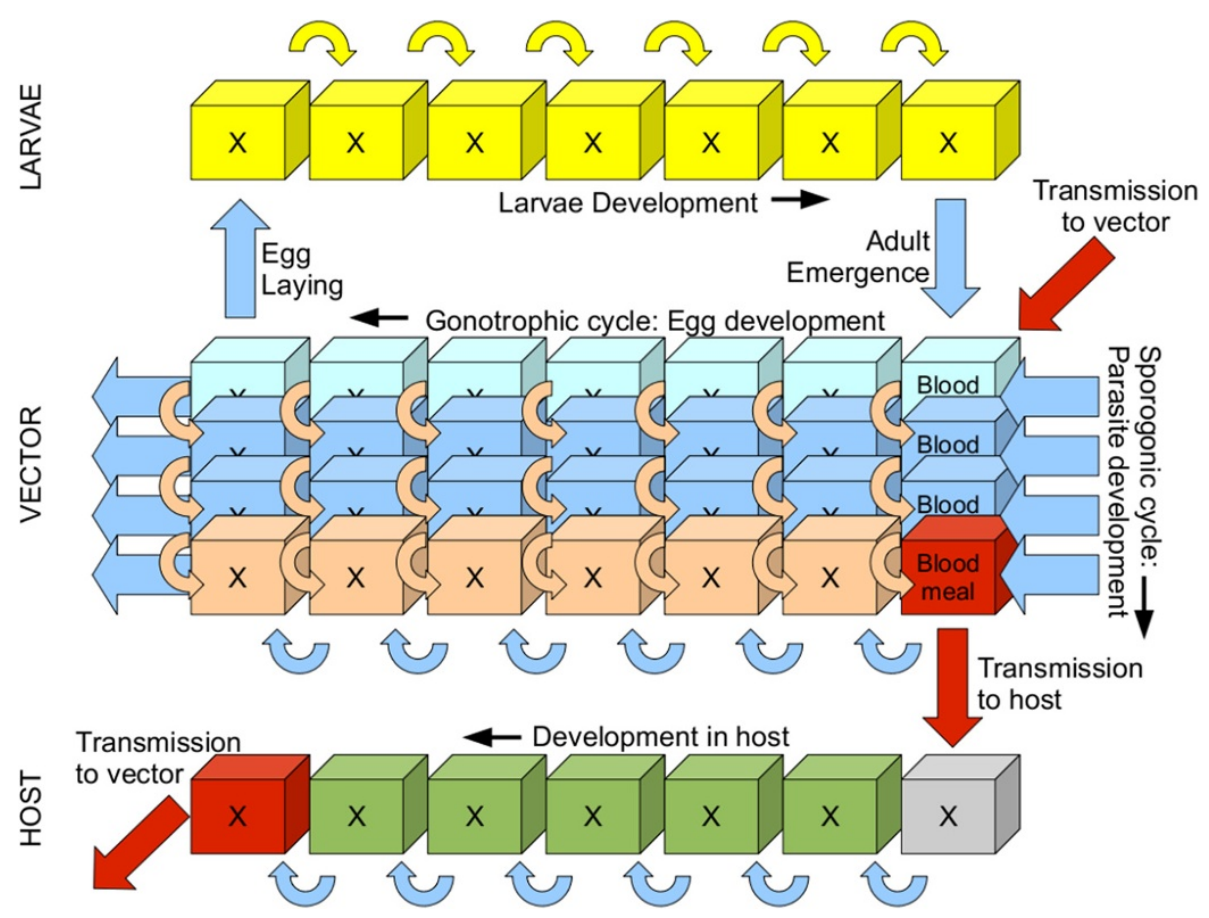

Figure 1 Schematic of the VECTRI model. The top row shows the larvae status divided into a series of bins representing the fractional development state. The ' $X$ ' in each bin represents the density of larvae in a specific fractional growth stage. The middle block represents the vector state in two dimensions: the egg development within the female and the infective state. The lower row models the host infective state. The curved arrows represent the progression direction of the larvae, vector and host state, while the straight red arrows mark the parasite transmission pathways between host and vector.

ensemble approach to assess model uncertainties, multiple parametrization choices are incorporated to facilitate this. All the constants are listed in Table 1.

\section{Larvae cycle}

Previous laboratory studies have shown that the larvae growth rate follows the degree day concept [46] based on a linear function of water temperature $T_{\text {wat }}$ above a threshold value $T_{L, \min }$ below which larvae growth ceases:

$$
R_{L}=\frac{T_{w a t}-T_{L, \min }}{K_{L}} .
$$

There is considerable uncertainty in the setting of the rate coefficient $K_{L}$, however, with [47] $K_{L}$ value of 90.9 degree days, while a linear approximation of the relationship derived by [48] results in a much slower rate of 200 degree days. A further source of uncertainty is the specification of the water temperature itself, which depends on the shading of the pool and its dimensions in addition to the ambient air temperature, and is described in the hydrology component below. VECTRI also permits the user to avoid this uncertainty by following [29] in setting a fixed larvae growth rate (i.e. independent of $T_{\text {wat }}$ ) to have a cycle of 12 days. The sensitivity to this relationship is investigated later. Irrespective of the scheme used, an upper temperature limit $T_{L, \max }$ is specified above which larvae death occurs.

Egg hatching into larvae and the pupae development stage are both typically on the order of one day $[48,49]$ and thus are poorly resolved by the daily timestep employed by VECTRI and other similar dynamical models. In order to avoid truncation problems the length is fixed in VECTRI to last exactly one day and is temperature independent.

\section{Larvae mortality}

The mortality rate of larvae is an important factor for transmission, and is strongly temperature dependent [50]. The VECTRI model sets a base daily survival rate for larvae $P_{L, \text { surv }}=0.825$ taken from [29], slightly lower than the values given by $[26,38]$. Development of larvae is negatively affected by larvae over-population due to competition for resources [51]. This is incorporated in VECTRI by reducing survival rate proportionally by a factor related to resource constraints:

$$
P_{L, \text { surv }}=\left(1-\frac{M_{L}}{w M_{L, \max }}\right) K_{\text {flush }} P_{L, \text { surv } 0} .
$$

In the first term on the right, $M_{L}$ is the total larvae biomass per unit surface area of a water body, and $w$ is the fraction coverage of a grid cell by potential breeding sites (not 
Table 1 VECTRI default constants

\begin{tabular}{|c|c|c|c|c|}
\hline Symbol & Value & Units & Description & Reference \\
\hline$E+1$ & 250 & $m m$ day $^{-1}$ & Total evaporation and infiltration losses & based on [85] \\
\hline$K_{L, \text { Jepson }}$ & 90.9 & K day & Larvae growth degree days & [47] \\
\hline$K_{L, B a y o h}$ & 200 & K day & Larvae growth degree days & [48] \\
\hline Kgono & 37.1 & K day & Gonotrophic cycle degree days & [46] \\
\hline$K_{\text {sporo }}$ & 111 & K day & Sporogonic cycle degree days & {$[46]$} \\
\hline$K_{\text {flush }, \infty}$ & 0.4 & & Larvae flushing factor for infinite rain rate & based on [27] \\
\hline$K_{w}$ & 1 & $m^{-1}$ & Pond growth rate factor & set by tuning or local knowledge of basin \\
\hline$K_{\text {mar } 1,0}$ & 0.45 & & Constant of Martens I vector survival scheme & [61] \\
\hline$K_{\operatorname{mar} 1,1}$ & 0.054 & ${ }^{\circ} \mathrm{C}^{-1}$ & Constant of Martens I vector survival scheme & {$[61]$} \\
\hline$K_{\text {mar } 1,2}$ & -0.0016 & ${ }^{\circ} \mathrm{C}^{-2}$ & Constant of Martens I vector survival scheme & {$[61]$} \\
\hline$K_{\text {mar } 2,0}$ & -4.4 & & Constant of Martens II vector survival scheme & {$[62]$} \\
\hline$K_{\operatorname{mar} 2,1}$ & 1.31 & ${ }^{\circ} \mathrm{C}^{-1}$ & Constant of Martens II vector survival scheme & {$[62]$} \\
\hline$K_{\text {mar2,2 }}$ & -0.03 & ${ }^{\circ} \mathrm{C}^{-2}$ & Constant of Martens II vector survival scheme & [62] \\
\hline$M_{L, \max }$ & 300 & $\mathrm{mg} \mathrm{m}^{-2}$ & Carrying capacity of water bodies & [38] \\
\hline$N_{\text {egg }}$ & 120 & & $\begin{array}{l}\text { Number of eggs per batch that result in } \\
\text { female vectors }\end{array}$ & [30] \\
\hline$P_{L, \text { survo }}$ & 0.825 & & Larvae base daily survival rate & {$[29]$} \\
\hline$P_{h v}$ & 0.2 & & $\begin{array}{l}\text { Probability of transmission from infective } \\
\text { host to vector during single bloodmeal }\end{array}$ & [29] \\
\hline$P_{v h}$ & 0.3 & & $\begin{array}{l}\text { Probability of transmission from infective } \\
\text { vector to host during single bloodmeal }\end{array}$ & {$[29]$} \\
\hline$T_{\text {wat }}$ & 2 & K & Pond water offset from air temperature & {$[92]$} \\
\hline$T_{L, \min }$ & 16 & ${ }^{\circ} \mathrm{C}$ & Minimum $T_{\text {wat }}$ for larvae development & based on [48] \\
\hline$T_{L, \max }$ & 38 & ${ }^{\circ} \mathrm{C}$ & Maximum $T_{\text {wat }}$ for larvae development & based on [48] \\
\hline$T_{\text {gono, } \min }$ & 7.7 & ${ }^{\circ} \mathrm{C}$ & Minimum $T_{2 m}$ for egg development & {$[46]$} \\
\hline$T_{\text {sporo, } \min }$ & 16 & ${ }^{\circ} \mathrm{C}$ & Minimum $T_{2 m}$ for sporogonic cycle & [29] \\
\hline$\tau_{\text {flush }}$ & 50 & $\mathrm{~mm}$ day $^{-1}$ & Larvae-flushing rainfall e-folding factor & based on [27] \\
\hline$\tau_{\text {zoo }}$ & 50 & $\mathrm{~km}^{-2}$ & Population density zoophilic factor & set by tuning \\
\hline$w_{\max }$ & 0.04 & & Maximum temporary pond fraction in cell & set by tuning or local knowledge of basin \\
\hline
\end{tabular}

List of constants in VECTRI.

open water) and is given by the surface hydrology component described below. If $w=0$, the survival rate $P_{L \text {,surv }}$ is also zero. The maximum carrying capacity, $M_{L, \max }$, is set to $300 \mathrm{mg} \mathrm{m}^{-2}$ and larvae mass is assumed to increase linearly with a stage 4 larva having a mean mass of $0.45 \mathrm{mg}$, both following $[22,38]$ closely. All larvae die above a water temperature of $T_{L, \text { max }}$.

Flushing of larvae by heavy rainfall has been suggested to be an important cause of larvae mortality [52,53]. Using an artificial pond apparatus [27], a $17.5 \%$ daily mortality rate of first stage larvae reducing to $4.8 \%$ for forth stage larvae was estimated, although the authors state that these figures could represent an underestimate due to the symmetry of the pond apparatus and the lack of sampling of more extreme rainfall amounts during the experiment campaign. On the other hand, vegetation in natural pools and the apparent ability for Anopheles gambiae larvae to take avoidance measures to avoid flushing could imply a lower flushing rate [54]. In order take the simplest possible relationship in VECTRI, flushing rate is represented as exponential function of rain rate, and is related linearly to the larvae fractional growth state $L_{f}$ :

$$
K_{f l u s h}=L_{f}+\left(1-L_{f}\right)\left(\left(1-K_{f l u s h, \infty}\right) e^{\frac{-R_{d}}{\tau_{f l u s h}}}+K_{f l u s h, \infty}\right),
$$

where $R_{d}$ is the rainfall rate in $\mathrm{mm} \mathrm{day}^{-1}, \tau_{\text {flush }}$ describes how quickly the effect increases as a function of $R_{d}$, and $K_{f l u s h, \infty}$ is the maximum value of $K_{f l u s h}$ for newly hatched 
first stage larvae at extremely high rain rates. In contrast the flushing effect is zero $\left(K_{\text {flush }}=1\right)$ at all rain rates for stage 4 larvae just prior to adult emergence $\left(L_{f}=1\right.$, corresponding to the larvae bin $i=N_{L}$ ). The relationship is illustrated in Figure 2. Since flushing is a function of daily rain rate at relatively high spatial resolution $\tau_{f l u s h}$ is set to $50 \mathrm{~mm} \mathrm{day}^{-1}$. In order to give mortality rates of first stage and forth stage comparable to [27] for typical daily rain rates in the tropics, a value of 0.4 is adopted for $K_{f l u s h, \infty}$.

\section{Gonotrophic cycle}

All female vectors are assumed to find a blood meal in the first night of searching, although this fraction can be set as a model parameter. Insecticide treated nets are, for example, able to frustrate host-seeking mosquitoes [55] and reduce the mosquito population number. It would depend on the human population and availability of animals. In this way both newly emerging and existing adult mosquitoes might be prevented from progressing in the feeding cycle.

Once the blood meal is taken, the egg development proceeds at a rate determined by the local 2 metre air temperature $T_{2 m}$, again following the degree day concept and is thus given:

$$
R_{\text {gono }}=\frac{T_{2 m}-T_{\text {gono,min }}}{K_{\text {gono }}} .
$$

At the end of the cycle the female vector lays $N_{\text {egg }}$ eggs that will eventually hatch into females; as is usual in such models, the eggs laid that result in the males are neglected. She subsequently cycles to the meal searching box. The number of eggs is highly variable and depends on vector species. The choice of $N_{\text {egg }}=120$, corresponding to a batch size of 240 assuming equality between the sexes, follows [30] but [56-58] indicate that this could be an overestimation. Present model development underway will permit stochastic variation of parameters such as $N_{e g g}$ in the future to account for their considerable degree of uncertainty in an ensemble modelling framework.

\section{Sporogonic cycle}

When the female vector takes a blood meal there is a certain finite probability that malaria transmission takes place, either from the host to vector or vice versa. The probability of transmission to the vector during a blood meal from an infective host is considered a constant $P_{h v}=$ 0.2 (following [29]), and thus the overall transmission probability $P_{h \rightarrow v}$ is the product of $P_{h v}$ and the proportion of hosts that are infective, namely the ratio of the population density of infected hosts $H_{\text {inf }}$ divided by the population density $H$ :

$$
P_{h \rightarrow v}=\frac{H_{i n f}}{H} P_{h v} .
$$

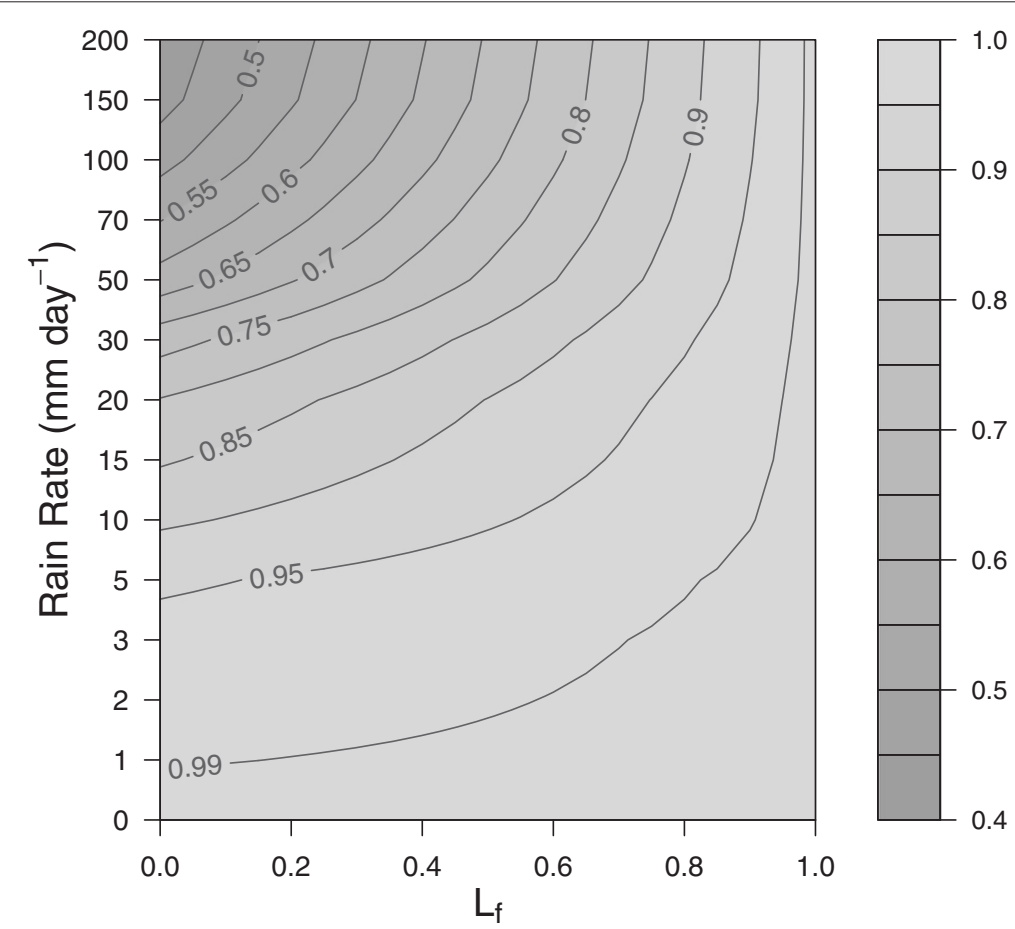

Figure 2 Larvae Flushing. Fractional reduction in larvae survival rate $\left(K_{\text {flush }}\right)$ as a function of larvae growth stage $\left(L_{f}\right)$ and rain rate as implemented in VECTRI. 
It should be noted that this assumes bites are randomly taken and not influenced by the host's infective state. Heterogeneous biting can impact the basic reproductive number considerably $[59,60]$. Heterogeneity of feeding habits is related to a wide array of factors, including host attractiveness to the vector and their vicinity to breeding sites, and heterogeneity in interventions such as the use of bed nets, in particular the increased use by hosts suffering from clinical malaria. Some of these effects could easily be included in VECTRI if relevant data were available.

Each timestep, a proportion of vectors $P_{h \rightarrow v}$ become infected, and the parasitic development in the midgut of the vector begins, once again governed by a degree day concept:

$$
R_{\text {sporo }}=\frac{T_{2 m}-T_{\text {sporo,min }}}{K_{\text {sporo }}} .
$$

After a number of days the sporozoites invade the salivary glands of the mosquito which subsequently becomes infective to humans. The mosquito is assumed to remain in this infective state until its death.

\section{Vector survival}

In addition to the larvae, gonotrophic and sporogonic cycles, temperature also plays a role in determining the mortality of vector. High air temperatures increase vector mortality, but the relationship is uncertain, especially at the high and low temperature bounds of transmission. As in the larvae cycle, two schemes are incorporated in the VECTRI model to permit a multi-model approach, with constants given in Table 1:

Scheme 1: follows $[52,61]$ and gives the survival rate as a quadratic function of temperature:

$$
P_{V, s u r v 1}=K_{m a r 1,0}+K_{m a r 1,1} T_{2 m}+K_{m a r 1,2} T_{2 m}^{2}
$$

Scheme 2: follows [62,63], revising the relationship as

$$
P_{V, \text { surv } 2}=\exp \left(\frac{-1.0}{K_{\text {mar } 2,0}+K_{\text {mar } 2,1} T_{2 m}+K_{\operatorname{mar} 2,2} T_{2 m}^{2}}\right)
$$

The results in this paper are obtained using scheme 2, referred to in [29] as Martens II.

\section{Host community}

One of the new aspects of the VECTRI model is that it explicitly allows the interaction between vector and host population on a district and regional scale. The VECTRI model specifies the population density $H$ using the Africaonly AFRIPOP [64] or global GRUMP [65] datasets which have a nominal $1 \mathrm{~km}$ and $4.5 \mathrm{~km}$ spatial resolution, respectively. Thus at each location (model spatial grid cell), the ratio of biting vectors to hosts is known and is given by $\left(\sum_{j=1}^{N_{\text {sporo }}} V(1, j) / H\right)$. This is important to represent the vector-to-host transmission rate. The number of bites $B$ that any particular individual receives in a given time the human biting rate $(h b r)$ is considered to be a random process, and thus distributed following a Poisson process with a mean biting rate of

$$
\overline{h b r}=\left(1-e^{\frac{-H}{\tau_{z o o}}}\right) \frac{\sum_{j=1}^{N_{\text {sporo }}} V(1, j)}{H} .
$$

The factor $1-e^{\frac{-H}{\tau_{z o o}}}$ represents the level of vector zoophily. While members of the Anopheles gambiae complex are in general considered anthropophilic to varying degrees [66], with arabiensis more zoophilic than sensu stricto [67], vectors take an increasing proportion of blood meals from cattle in lower population density rural areas with high livestock numbers [68], although the effectiveness of zooprophylaxis is still debated [69]. The exponential factor reflects this, with the e-folding population density for the effect set to $\tau_{z o o}=50 \mathrm{~km}^{-2}$. Thus the factor only has a significant impact for rural populations below this number and avoids the model producing excessively high biting rates and EIR for sparsely populated locations. In future, VECTRI will allow vector movement between cells allowing anthropophilic vectors to cluster around population centres.

The daily number of infectious bites by infectious vectors, $E I R_{d}$, is the product of $h b r$ and the circumsporozoite protein rate $(C S P R)$. Specifically in the VECTRI notation, this is $V\left(1, N_{\text {sporo }}\right) / H$, with the 1 indicating that the calculation is restricted to the vectors that are biting within the present timestep of the model. This implicitly assumes that there is no change in the intensity of biting or the gonotrophic cycle length between uninfected and infectious vectors; a simplification according to [70]. If the transmission probability from vector to host for a single bite of an infective vector, $P_{v h}$, is assumed a constant then the transmission probability for an individual receiving $n$ infectious bites will be $1-\left(1-P_{v h}\right)^{n}$. The impact on transmission due to blocking immunity is neglected. Thus the overall transmission probability per person per day in the model can be obtained by the integration over the bite distribution:

$$
P_{\nu \rightarrow h}=\sum_{n=1}^{\infty} G_{\overline{E I R_{d}}}(n)\left(1-\left(1-P_{v h}\right)^{n}\right)
$$

where $G_{\overline{E I R_{d}}}$ is the Poisson distribution for mean $\overline{E I R_{d}}$. If bed nets are in use, eqn. 11 could be modified to incorporate this, increasing the mean bite rate for a subset of the unprotected population. This involves a number of complications however, since accurate data would be required concerning bed net distribution and use, how this usage correlates to host infective state, and which proportion of bite are taken during the hours of sleeping. 
The impact of using eqn. 11 is to reduce the mean transmission rate, particularly when the mean bite rate is small, resulting in a strong positive skewness of the Poisson distribution (Figure 3). While this is an improvement on the simple assumption that all hosts receive equal numbers of bites, the Poisson distribution is likely underdispersive compared to reality, since a number of factors such as unequal host attractiveness to vectors and nocturnal behaviour affecting exposure will likely lead to an uneven distribution of biting rates [71-73]. Figure 3 also emphasizes that the model is relatively insensitive to the choice of $P_{v h}$ for values exceeding around 0.2. The default value that VECTRI adopts for $P_{v h}$ is 0.3 following [29], but there is considerable uncertainty in this parameter, which also depends on immune status, with [74] reporting that half of a small group of 10 malaria naive volunteers were infected after being exposed to 1 to 2 infective bites, while [75] estimated a value of just 1 in 13 in an endemic area.

The host population is represented by the vector $H\left(N_{h o s t}\right)$, and each VECTRI timestep a proportion $P_{v \rightarrow h}$ of hosts become infected and progress through the array until 20 days later they assume an infective status, an average value for immune and non-immune subjects [76-79]. Non-immune hosts clear infections at an e-folding rate of $C_{n i}=150$ days. Even after a century of study of the disease, the paradigm of naturally acquired immunity (NAI) is still hotly debated [21]. Therefore the present version of the model neglects host immunity, and the impact of the various representations of immunity in VECTRI will be the subject of a companion article.

\section{Surface hydrology}

The VECTRI model includes a simple, physically-based surface hydrology model that at each timestep provides a calculation for the fractional coverage of each model gridcell by potential breeding sites for the malaria vector, $w$. This fraction consists of two components since the model distinguishes between breeding sites provided by temporary ponds, $w_{\text {pond }}$, and those associated with permanent water bodies such as lakes, rivers and streams that contain water year-round, $w_{\text {perm }}$ :

$$
w=w_{\text {perm }}+w_{\text {pond }} .
$$

Considering first $w_{\text {perm }}$, converting land use and terrain information into a fractional coverage of breeding areas provided by permanent water bodies is a significant challenge. Wave/ripples action that can drown larvae [80] and the presence of predators in larger bodies [81] imply that larvae exist only in a sub-fraction of such water bodies, in pooling that occurs on the edges of lakes and rivers or the shallow edges of ponds. Higher soil moisture in the

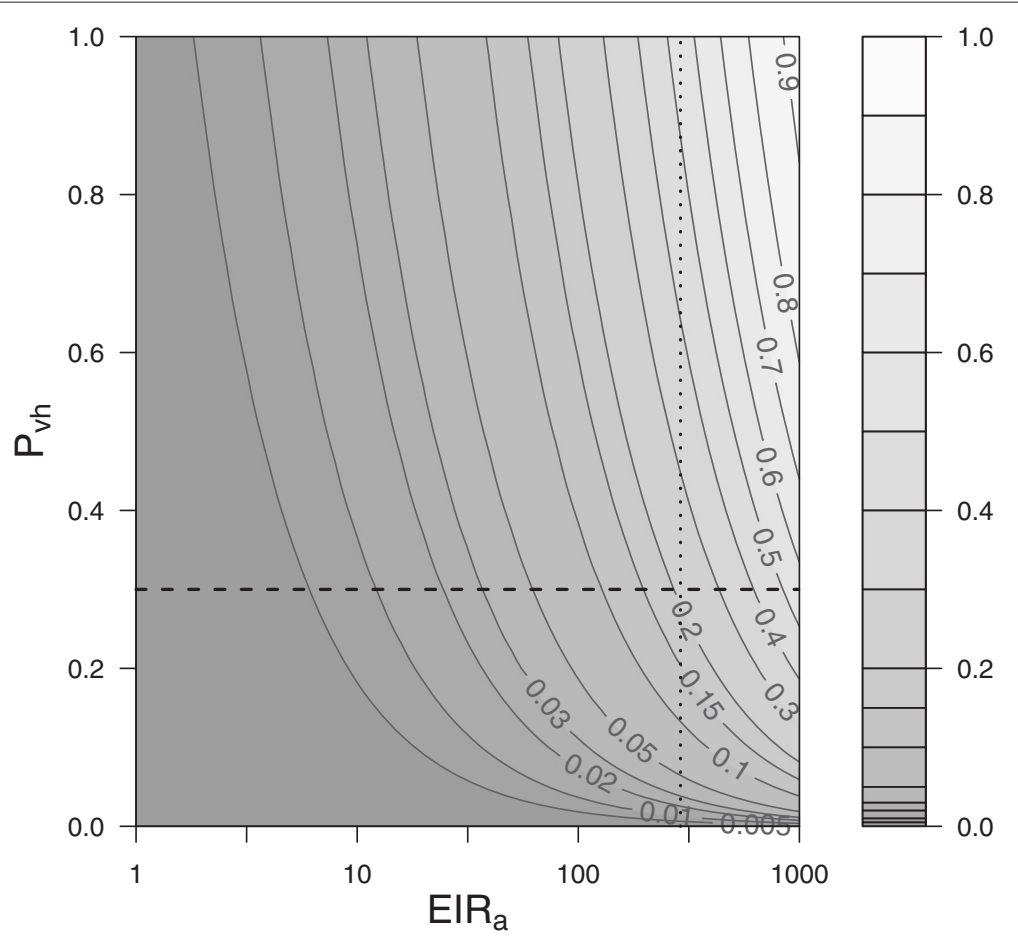

Figure 3 Vector to host transmission. Contour plot of $P_{v \rightarrow h}$ as a function of $P_{v h}$ and $E I R_{a}$. The horizontal dashed line highlights $P_{v h}=0.3$ as specified by the default VECTRI model. The vertical line marks $E I R_{a}=365$, for which $P_{v \rightarrow h}$ would equal $P_{v h}$ if the distribution in biting rate were not taken into account. 
vicinity of large water bodies can boost available breeding sites by reducing infiltration loss and increasing the lifetime of temporary puddles and ponds. Lastly, rivers and streams can even confound classic relationships between rainfall and vector density by actually providing more breeding sites during drought periods when flow slows or stops altogether [82]. This remains the subject of current research and the default VECTRI model therefore sets $w_{\text {perm }}$ to zero in each grid cell, implying that the breeding site availability is dominated by seasonal ephemeral ponds and malaria incidence will be potentially underestimated in the vicinity of larger semi-permanent water bodies. A user operating the model for a local area with knowledge of permanent water bodies can set this value appropriately.

The net aggregated fractional coverage by temporary pools $w_{\text {pond }}$ is derived from a simple water balance model. Ponds are replenished by surface runoff $Q$, while infiltration $I$ (seepage) and evaporation $E$ and pond overflow reduce their water content. An important parameter is the maximum coverage of the temporary ponds $w_{\max }$, which described the extent of depressions that could potentially become water filled at the peak of a wet season, which are often small in scale, with total catchments of the gully systems studies in Niger in the HAPEX-SAHEL experiment measuring $0.2 \mathrm{~km}^{-2}$ [83]. Presently it is assumed that the runoff $Q$ that fills the ponds mostly falls within these depressions and thus the runoff is set to $Q=w_{\max } P$, where $P$ is the precipitation rate. Thus sub-surface infiltration occurring within the depressions is also considered a water source for temporary pools [83]. Future developments will introduce an improved runoff treatment accounting for soil texture and slope.

The source from precipitation is balanced by evaporative, infiltration and overflow losses. In high-resolution simulations of surface hydrology in Niger, [84] found overflow losses to be approximately $20 \%$ of total losses, more than three times the losses due to evaporation. It should also be noted that overflow losses in field campaigns are difficult to measure and thus are often incorporated in the infiltration, which is calculated as a residual in the water balance calculation. Losses through pond overflow are assumed to increase linearly with pond fraction in VECTRI, achieved by scaling the runoff by a factor $1-\frac{w_{\text {pond }}}{w_{\max }}$. Once the pond fraction reaches its maximum, all surface runoff overflows and is lost. Infiltration losses vary substantially depending on soil texture and life-scale of the pond in question. Often the infiltration is a highly nonlinear function of water body extent, since silting may significantly reduce infiltration in the lowest part of longer-lived or semi-permanent pools [83]. This results in a fast initial decay after rain events due to high infiltration rates at the pool edges, followed by a slower decay, while temporary, shorter lived water bodies tend to have more uniform infiltration rates. These rates can be very high, exceeding $600 \mathrm{~mm} \mathrm{day}^{-1}$ [85]. Presently the VECTRI model simply sets a fixed constant infiltration rate per unit pond area.

Combining these factors, the volume of water $v_{\text {pond }}$ in ponds per unit area thus evolves as

$$
\frac{d v_{\text {pond }}}{d t}=w_{\max } P\left(1-\frac{w_{\text {pond }}}{w_{\max }}\right)-w_{\text {pond }}(E+I) .
$$

Evaporation is set to $5 \mathrm{~mm}$ day $^{-1}$, equivalent to a latent heat flux of $145 \mathrm{Wm}^{-2}$. It is possible to derive evaporation losses from water temperature, and atmospheric wind speed and relative humidity, however, as evaporation is a relative minor loss term relative to infiltration and overflow, a simple fixed evaporation rate suffices. With $I$ set to a reasonable value of $245 \mathrm{~mm} \mathrm{day}^{-1}$, total losses from infiltration and evaporation are thus $250 \mathrm{~mm}^{\text {day }}{ }^{-1}$. For closure, the pond fractional coverage needs to be related to the volume. Individual ponds have been modelled previously using a power law approximation [86], which would lead to a relationship $\frac{d w}{d t} \propto w^{-p / 2} \frac{d v}{d t}$, where $p$ is the power law exponent. However, [86,87] show that $p$ can vary by almost an order of magnitude from one water body to another and depends in particular on the lifetime. In the present version model this factor is neglected and the coverage is simply linearly related to pond coverage introducing a tunable factor $K_{w}$ :

$$
\frac{d w_{\text {pond }}}{d t}=K_{w}\left(P\left(w_{\max }-w_{\text {pond }}\right)-w_{\text {pond }}(E+I)\right) .
$$

As the pond coverage can change rapidly, eqn. 14 is integrated using a fully implicit solution. An example evolution of the fractional pond coverage for a site near Bobo-Dioulasso is given in Figure 4, which shows that the simple empirical approach mimics the pond evolution modelled by high resolution hydrological models for sites in Niger [38] and ponds modelled in Senegal [88]. The present empirical formulation is similar to the approaches of $[23,37]$. It is seen that at the fringes of the rainy season, puddles and small ponds have limited longevity on the order of a few days, implying that they are unsuitable for vector breeding. VECTRI represents the bulk behaviour of ponds, rather than the ultra-high resolution model of [84] which individual models puddles at the $10 \mathrm{~m}$ scale and thus can model the lifetime of ponds as a function of their explicit size (see their Figure Seven). Obviously, the linear relation between rainfall and the growth of potential breeding sites in parameter $K_{w}$ is a simplification, while the other terms should be related to atmospheric conditions, soil type, vegetation coverage and terrain slope demonstrated to be important for malaria transmission in the Kenyan highlands [89]. 


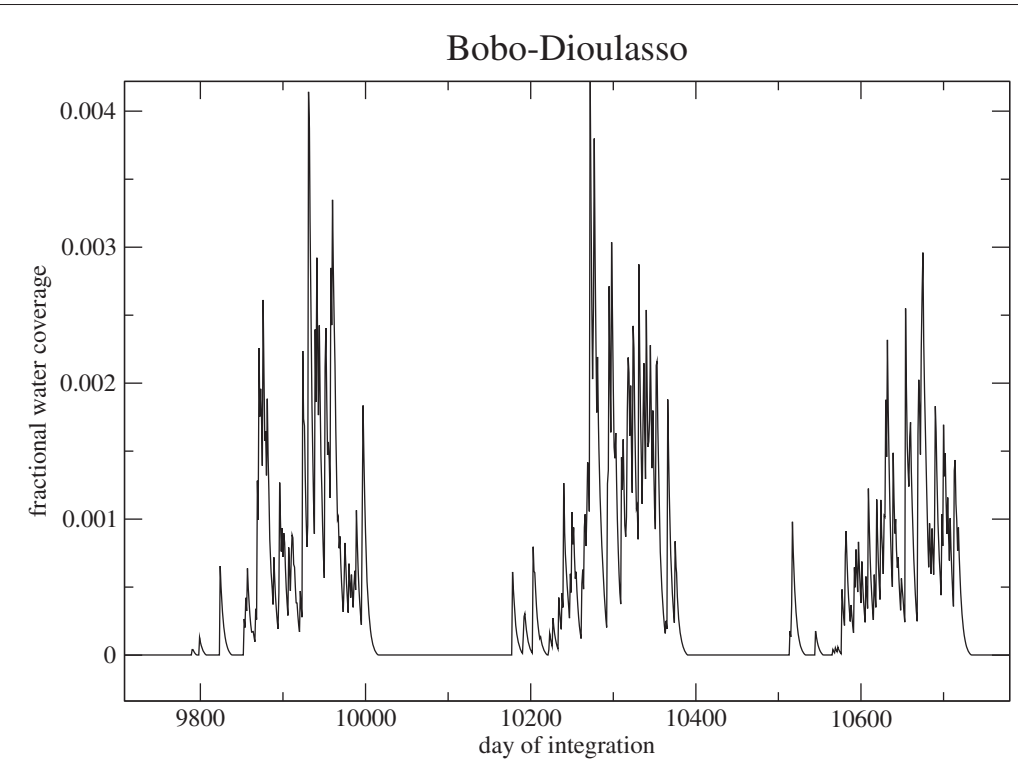

Figure 4 Surface hydrology. An subsection of a multi-year VECTRI integration for Bobo-Dioulasso showing the evolution of model water fraction for three rainy seasons.

Presently, the two unknowns $w_{\max }$ and $K_{w}$ in the framework are set using a simple Monte Carlo suite of station data integrations in a subset of locations to minimize EIR errors compared to field data. An example sensitivity integration is shown in Figure 5, which is a integration conducted for Bobo-Dioulasso using station data to drive the model (see below for experimental set up details). It is seen that transmission intensity increases with $w_{\max }$ and $K_{w}$ as expected, since these increase the pond coverage for a given rain rate, while increasing the loss rate acts in the opposite direction. For a given station there are a range of reasonable parameter values, with the present parameter settings chosen using a small number of locations in West Africa. Nevertheless, the physically based framework facilitates future improvement currently underway, which will include direct validation of the revised hydrological model constants using in situ and remotely sensed data.

Finally, it is recalled that the pond dimension limits larvae mortality rates through the availability of breeding sites governed in eqn. 3. This is an approximation of the net affect of crowding which leads to higher mortality rates, longer development times and smaller adults [90], which in turn have a competitive disadvantage [58]. The biomass is considered to be distributed equally through all available breeding sites and variability between breeding sites in neglected, supported by [91] who noted that females avoid ponds that are overcrowded with existing larvae.

In addition to pond dimension the other important parameter of water bodies is the temperature of the water near the surface. The Depinay model [22] developed a complex empirical function for water temperature as a function of ambient relative humidity and water body size. As the VECTRI model is applied regionally, specific information about individual water body size may not be included. The temperature in shallow ponds and puddles is homogeneous to a good approximation and is often one or two degrees warmer than the air temperature $[92,93]$. VECTRI therefore assumes that the temperature of pools $T_{\text {wat }}$ to have a fixed offset relative to the air temperature. The default value adopted is a positive offset of $2 \mathrm{~K}$, however, in hot locations it is likely that vector will preferentially choose shaded breeding locations and a lower or even negative offset may be more appropriate. If accurate gridded weather information for wind and surface radiation were available, this aspect of the model could be potential improved implementing a single energy balance model along the lines of $[94,95]$. While larger permanent water bodies such as lakes and rivers can have complex stratification of the vertical temperature profile, as discussed above, larvae development occurs mostly in the shallow waters and pools that form on the lake/river boundaries and thus the temperature relation for the permanent water fraction is treated in the same way as the temporary ponds.

\section{Evaluation of VECTRI \\ Evaluation methodology and data}

VECTRI is evaluated using a series of three testbed arrangements. The first test determines the sensitivity of the force of infection measured by EIR in relation to 


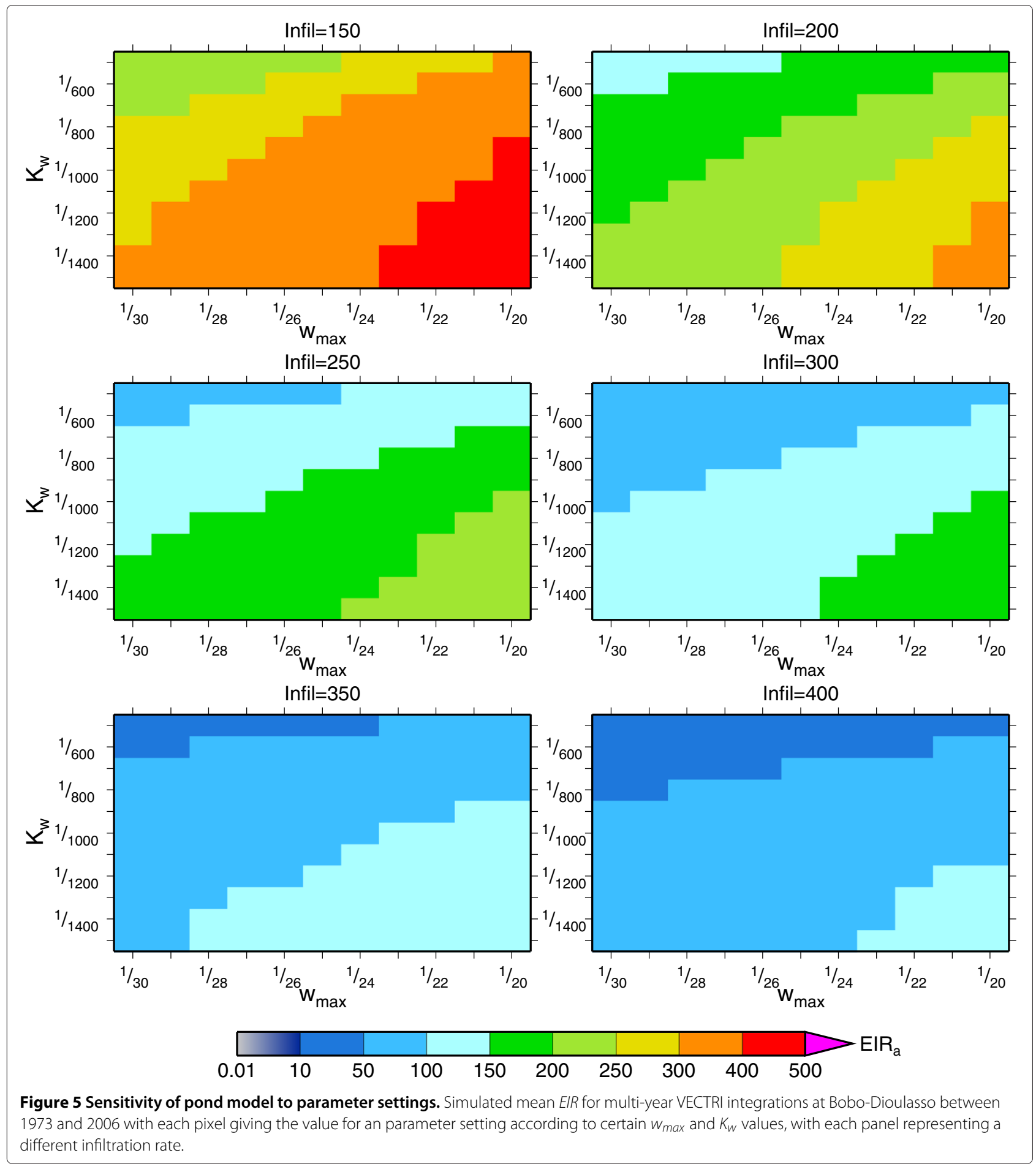

climate in an idealized setting of so-called 'equilibrium runs.' The model is driven to equilibrium in an array of experiments using constant values of temperature and rainfall and compared to the reference model described below.

The VECTRI model is next confronted with a wide range of entomological data consisting of EIR and circumsporozoite protein rate (CSPR) measurements collected from field campaigns located throughout West and Central Africa and which were collated in a review by [96]. These campaigns are divided between rural and urban environments. In particular, the availability of a large number of both peri-urban and rural field studies in and nearby Bobo-Dioulasso documented in [97-106] lead 
to this location being used as a focus site. For each location, the models are driven by daily weather data from the nearest available station, which for points in or nearby population centres is often within $10 \mathrm{~km}$, but can be much further for isolated rural locations. A simple interpolation methodology is used to fill temporal data gaps [96]. While the malaria field campaigns are often only available for a single year, and never more than a few seasons, the malaria models are integrated for over four decades to give an indication of interannual variability, with results from these 'station integrations' shown from 1973 to 2006.

Lastly, the malaria prevalence is evaluated from 'regional integrations' conducted with VECTRI, the first in Eastern Africa (domain $27^{\circ} \mathrm{E}-42^{\circ} \mathrm{E}$ and $12^{\circ} \mathrm{S}-6^{\circ} \mathrm{N}$ ) and the second for West Africa $\left(18^{\circ} \mathrm{W}-9^{\circ} \mathrm{E}\right.$ and $4.5^{\circ} \mathrm{N}$ to $\left.19.5^{\circ} \mathrm{N}\right)$. Integrations last for 10 years and use a horizontal spatial resolution of 0.1 degrees, equivalent to approximately $11 \mathrm{~km}$. As freely available daily station data is sparse, the model is instead driven with satellite-derived rainfall using the NOAA FEWS RFE product [107], available from late 2000 to the present on a $11 \mathrm{~km}$ resolution which is interpolated to the VECTRI grid using conservative remapping. The gridded 2 metre height temperature data is taken from the ECMWF ERA-Interim reanalysis product [108]. As the resolution of the reanalysis is relatively coarse at approximately $75 \mathrm{~km}$ in the tropics, it is statistically downscaled using a constant adiabatic lapse rate of $6.5 \mathrm{~K} \mathrm{~km}^{-1}$ [109] to correct for the height error between the model topography and the ETOPOv2 topography [110] bilinearly interpolated to the VECTRI grid. Starting from artificial initial conditions of $5 \%$ of the population carrying the parasite, the model is integrated for a spin up period of 3 years cycling the first year of weather data to allow the malaria loading in the population to equilibrate before the integration runs freely. Focus is on the integration for Eastern Africa due to the wide range of topography and the consequential inclusion of malaria free, epidemic and endemic zones, which are compared to the MAP malaria analysis [111-113]. The MAP analysis ingests $P R$ survey data occurring up to 2010 into a statistical model that also incorporates environmental data to provided gridded values of $P R$ [114]. The reliability of the MAP data depends on the local availability of survey data. In Africa, for most areas there is a large uncertainty of the MAP prediction. For example, the prediction is less certain for Uganda and Tanzania, which represent under-surveyed countries. More certain is the MAP analysis for most parts of Kenya, although [113] marks the coastal and western regions with high uncertainty despite the far greater densities of survey data available there. The two regional runs are thus also compared to direct survey data from 199 field campaigns using the analysis of [33] in order to assess the impact of population density on EIR.

\section{Comparison model}

The VECTRI model is contrasted to the Liverpool Malaria Model (LMM), which has been applied in various forms to regional malaria modelling across Africa for both seasonal timescale forecasting [24] and to investigate climate change impacts on transmission [115]. The original version of LMM described by [26] was updated in terms of its surface hydrology by $[29,30]$, and referred to here as $\mathrm{LMM}_{2010}$. The $\mathrm{LMM}_{2010}$ is a dynamical mathematicalbiological malaria model, which is driven by the two variables of daily mean temperature and precipitation. The treatment of surface hydrology in $\mathrm{LMM}_{2010}$ differs significantly to VECTRI. It applies a fuzzy distribution model to relate egg-larvae development to the decadal (10 day accumulated) rainfall amount, with optimal conditions assumed to occur with $1 \mathrm{~mm}$ day $^{-1}$ average rain rate. Egg-laying rates are reduced below $1 \mathrm{~mm} \mathrm{day}^{-1}$ rain rates to reflect the lack of breeding sites, and also above this threshold since flushing effects are then assumed to dominate. The use of a ten day average rainfall essentially equates to the assumption that rainfall feeds ponds and pools which have a ten day mean lifespan. Water temperatures are not considered by the $\mathrm{LMM}_{2010}$ in the egg-larval development rates.

The $\mathrm{LMM}_{2010}$ uses similar entomological and parasitological numerical components to VECTRI. By contrast, the $\mathrm{LMM}_{2010}$ neglects the population density and is only calibrated to malaria observations from rural locations in West Africa. This means that the $\mathrm{LMM}_{2010}$ is not able to simulate urban malaria conditions. The model is also not valid for irrigated malaria areas, where malaria transmission is not depending solely on rainfall. The vector-host contact is furthermore static in the $\mathrm{LMM}_{2010}$ since a fixed proportion of the mosquito bites is taken up by humans and animals.

\section{Results and discussion}

\section{Equilibrium integrations}

The VECTRI model is driven to equilibrium in an array of experiments using constant values of temperature and rainfall, and compared to the reference $\mathrm{LMM}_{2010}$ (Figure 6). In terms of temperature, the range at which malaria transmission occurs $(E I R>0.01)$ of 18 to 37 degrees is similar to the $\mathrm{LMM}_{2010}$, although the upper limit is controlled by the maximum in water temperature and thus is lower than the $\mathrm{LMM}_{2010}$, which ignores the impact of water temperature. It is noted that, unlike larvae which have limited potential to avoid high water temperatures, mosquitoes are able to change behaviour such as resting habits to avoid extreme air temperatures [116]. Therefore, the usual attribution of the upper temperature limit of malaria transmission to excessive vector death, as also determined by the $\mathrm{LMM}_{2010}$, may be misleading. On the other hand, the water temperature is an uncertain 


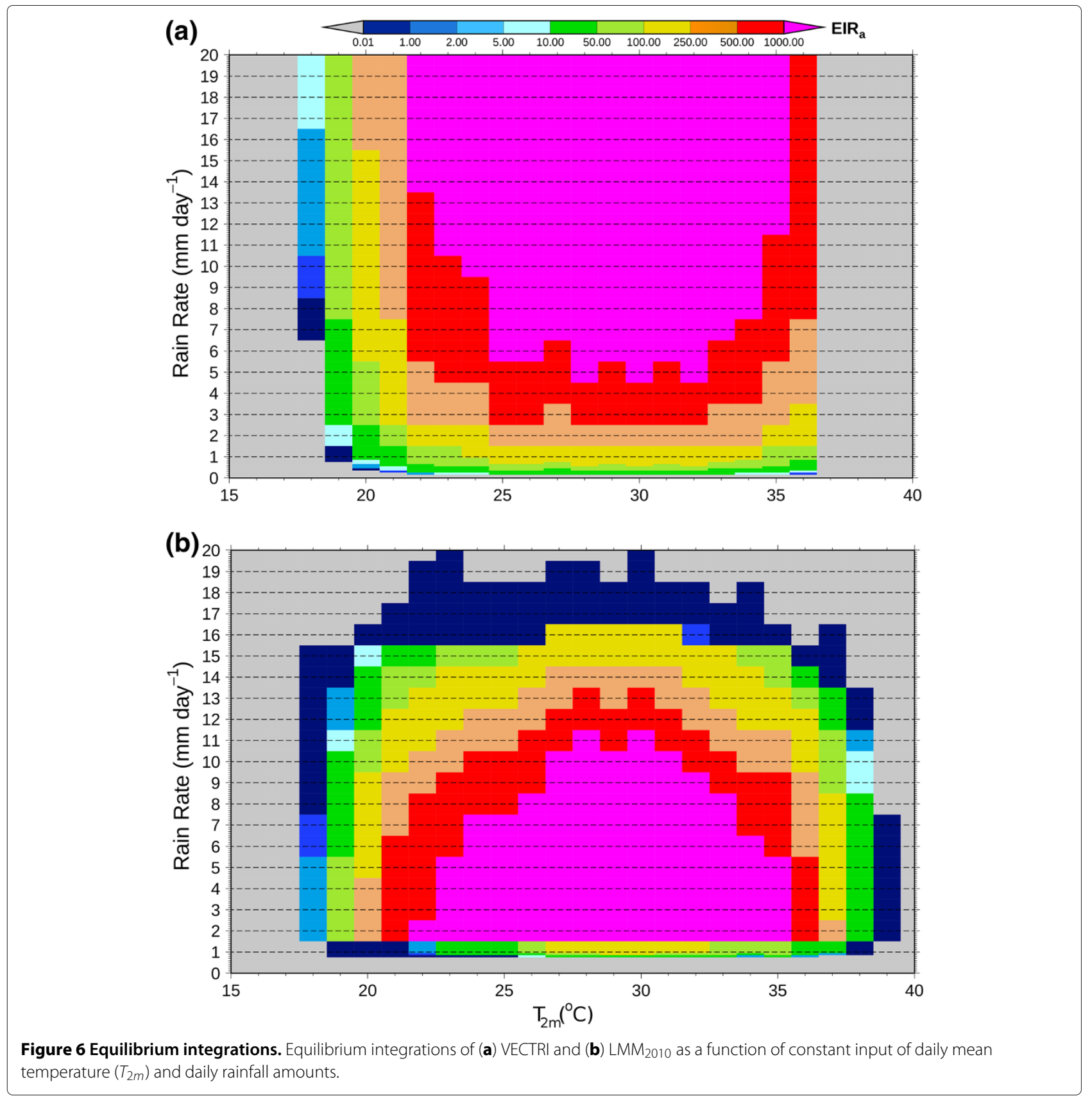

parameter, and greatly variable shading and availability of sites in a grid cell may imply the water temperature is a less important parameter than indicated by VECTRI.

In terms of rainfall sensitivity, the two models differ considerably. The nonlinear function that determines number of egg laid as a function of rainfall in the $\mathrm{LMM}_{2010}$ model is very sensitive to rainfall. As the rain rate deviates from the assessed ideal value of $1 \mathrm{~mm} /$ day, the EIR decreases quickly. Thus in the rainy season, when daily rainfall amounts usually exceed $1 \mathrm{~mm}$ /day, it is likely that the LMM will produce an anticorrelation between rainfall amount and malaria transmission intensity. Instead, although the VECTRI model includes a flushing parametrization, the effect is much weaker at these moderate rain rates of 0 to $20 \mathrm{~mm} \mathrm{day}^{-1}$ and rainfall is therefore positively correlated with transmission intensity. Moreover, above 2 to $3 \mathrm{~mm} \mathrm{day}^{-1}$, the sensitivity of EIR to rain rate is much lower in VECTRI than $\mathrm{LMM}_{2010}$, which is likely to result in a lower interannual variability of malaria in endemic regions in the former model. 


\section{Station integrations}

A summary of the results for a selection of stations across the region (Figure 7) the control model LMM 2010 agrees well with the range of $E I R$ values, which is not surprising, considering these data were used to calibrate the model settings. Although VECTRI was not calibrated with the data, at seven of the eight locations the rural VECTRI $E I R_{a}$ values overlap with the field observations meaning that the VECTRI runs produce realistic transmission values for most parts of West Africa. In comparison to the LMM 2010 , VECTRI shows a much smaller year-toyear variability and some field observations lie outside the range of the model interannual variability. To a certain extent, this is to be expected, since the model is only able to simulate the interannual variability due to climate - other factors such as interventions are neglected. Instead, the LMM is calibrated to reflect all variability in the observations in its sensitivity to rainfall and temperature, as seen in the earlier equilibrium integrations. That said, VECTRI underestimates the malaria transmission in the northern Sahel. Too small transmission values are simulated by VECTRI in Podor for example. Transmission in urban areas appears to be under-simulated, and in two urban locations in Dakar no transmission at all occurs in the model. Further south, where more rainfall occurs during the monsoon season, VECTRI in general simulates somewhat too high $E I R_{a}$ values in comparison to the rural observations. VECTRI also seems to simulate too high transmission values in equatorial Africa in Douala, which is subject to high annual rainfall rates. The simulated $E I R_{a}$ values exceeding 500 infectious bites per human per year are rarely observed in Africa with 13 surveys out of a total of 180 reported by [32] registering EIR in this range.

A further detailed analysis is made for Bobo-Dioulasso in southwest Burkina Faso, which was chosen due to a particularly large number of field experiments with which to compare the models. Malaria is seasonally endemic in this location and a number of field campaigns have sampled EIR and CSPR in both (peri) urban and rural (some with nearby irrigation schemes) environments [97-106]. Only one integration is conducted for the $\mathrm{LMM}_{2010}$ since it is unable to account for population density. This is compared to two VECTRI integrations representative of rural (latitude $11.43^{\circ} \mathrm{N}$, longitude $4.25^{\circ} \mathrm{E}$, human population density $H=32.2 \mathrm{~km}^{-2}$ ) and urban (latitude $11.2^{\circ} \mathrm{N}$, longitude $4.30^{\circ} \mathrm{E}, H=1040 \mathrm{~km}^{-2}$ ) field locations. The timeseries of annual EIR and CSPR values from the 3 integrations (Figure 8) show that both models reproduce the correct order of magnitude for these two variables in the rural location. The EIR in the VECTRI model and LMM 2010 lie within the spread of measured EIR. The significant variability between the observed EIR values is noted, which could derive from differences in terrain, topography, altitude, vicinity to water bodies, irrigation and land use,
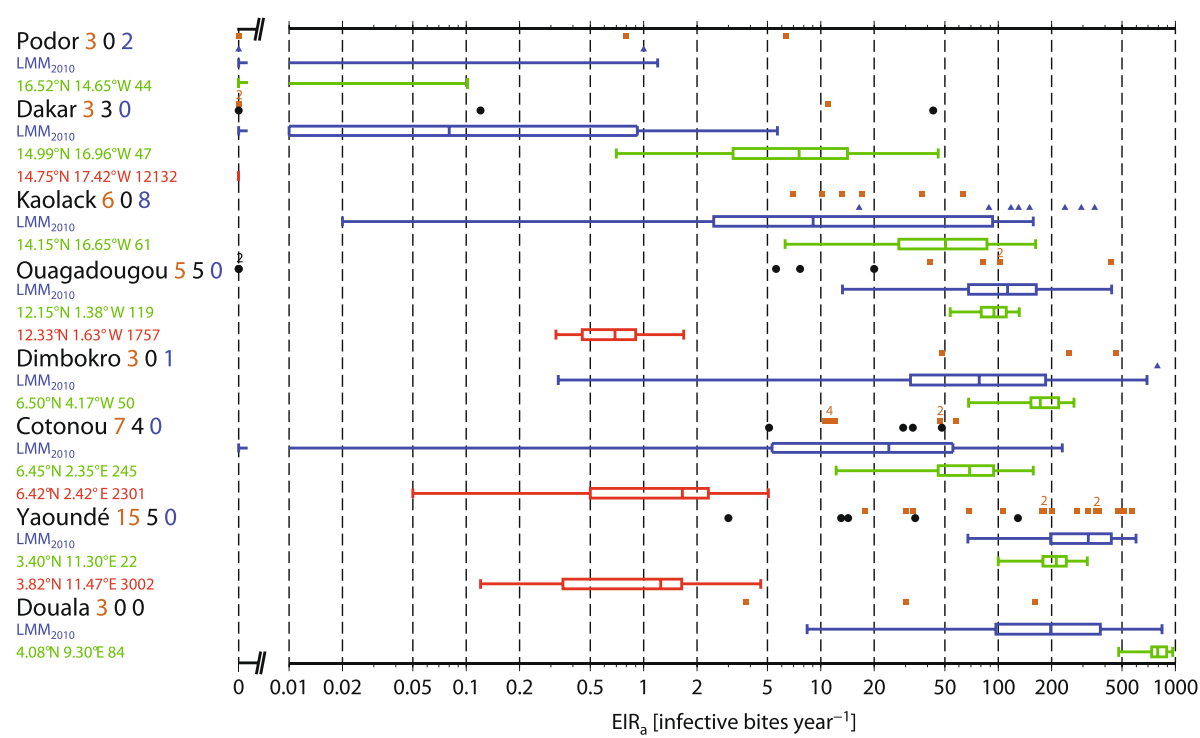

Figure 7 Observations and simulations of EIR and CSPR. Box-and-whisker plots of the VECTRI and LMM 2010 simulated annual Entomological Inoculation Rate (EIRa; in infectious bites per human per year) for eight West African locations. The box-and-whisker plots of the LMM $\mathrm{LM}_{2010}$ are illustrated in blue. VECTRI results in terms of rural and urban areas are taken green and red, respectively. Also the latitudinal, longitudinal position, and used population density $\left(\mathrm{km}^{-2}\right)$ is indicated. Climate varies from a semi-arid (Podor) to a tropical climate (Douala). Field ElR $a$ observations are furthermore included as brown squares, black dots and blue triangles in rural, urban and irrigated areas, respectively. The number of field observations is entered behind the location names in the following order: 1) rural, 2) urban, and 3) irrigated observations. The number of clustered observations on the logarithmic scale is indicated by a digit above the symbols. 


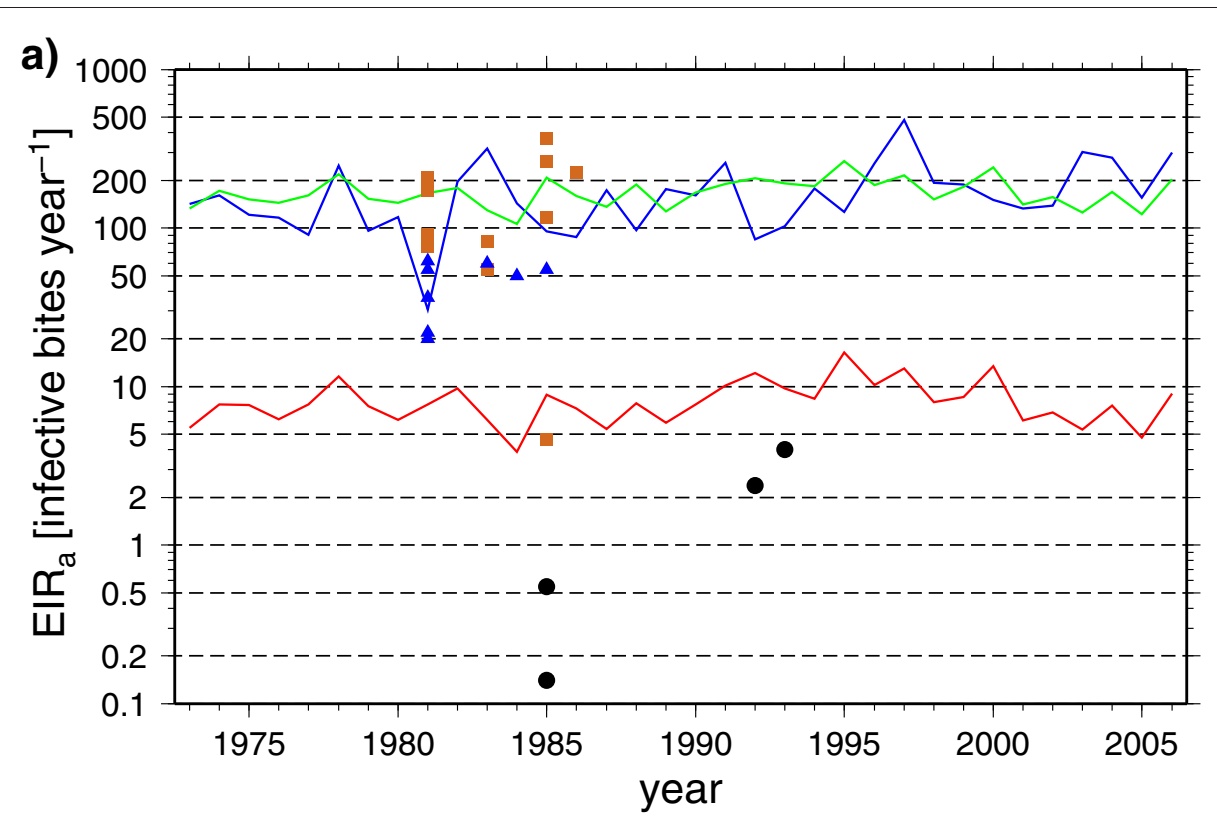

b)

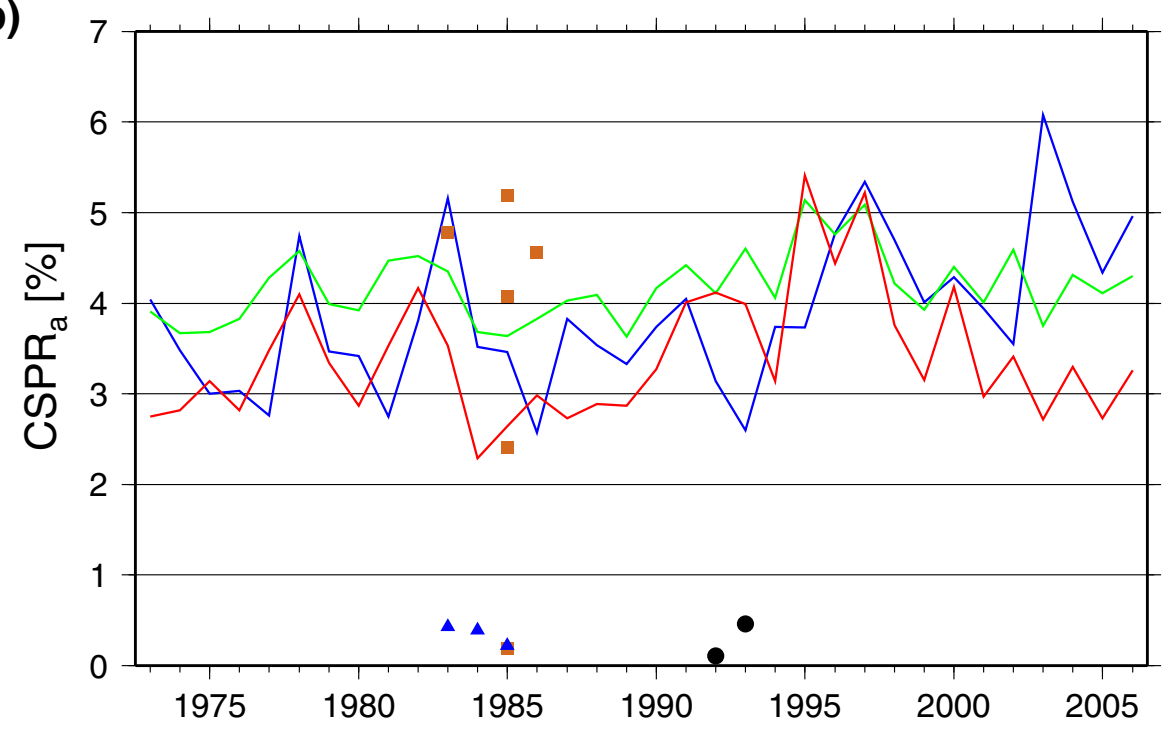

Figure 8 EIR and CSPR interannual variability in Bobo-Dioulasso. Simulated and observed malaria transmission in the area of Bobo-Dioulasso. (a) Annual EIR rates (EIR ; in infectious bites per human per year) and (b) annual mean CSPR (CSPR ; in \%). The blue lines represent $L_{M M} 2010$ and the red and green lines VECTRI simulations (red: human population density $H=1037 \mathrm{~km}^{-2}$; green: $H=32.2 \mathrm{~km}^{-2}$ ). The brown squares, blue triangles, and black dots stand for observed EIR and CSPR $R_{a}$ values in rural, irrigated and urban areas, respectively. See [30] for a definition of rural, irrigated and urban areas and for the sources of the field observations (their Additional file Two; the Word Meteorological Organisation (WMO) station number 65510 of Bobo-Dioulasso is assigned to the data).

interventions and simply experimental sampling error. It emphasizes the uncertainty in individual measurements and the need for ensembles of experiments to gauge this uncertainty. The EIR is generally lower in rural locations with irrigation, possibly as a result of preditor establishment in longer-lived pools but may also be due to irrigation providing farmers with higher incomes permitting further prevention and treatment measures. This emphasizes the difficulty in gauging such influences in the $w_{0}$ parameter of the VECTRI model.

Intercomparing EIR from the two malaria models, the very high interannual variability of the $\mathrm{LMM}_{2010}$ is obvious, related to its elevated sensitivity to rainfall demonstrated in the earlier constant-input experiments. The $\mathrm{LMM}_{2010}$ EIR value ranges by more than an order of magnitude between the lowest and highest year, while 
the interannual variability is less than a factor of two for the VECTRI model. It is interesting to note that, despite the basic underlying structure being very similar in the two models, the parametrization choices, in particular the implementation of the surface hydrology in the VECTRI model, results in almost a zero correlation between the two models in their representation of interannual variability; indeed, the EIR appear anti-correlated indicating that rainfall variability is determining the interannual variability to a large extent.

The black squares in the figure give EIR values for high population areas in peri-urban Bobo-Dioulasso, which are much smaller than in the rural environments but nevertheless non-zero. The $\mathrm{LMM}_{2010}$ is not designed to simulate these urban cells, however the VECTRI model is seen to reproduce reasonably well the contrast between rural and urban areas. Even though the treatment of the surface hydrology is identical in urban and rural environments - a gross oversimplification - the VECTRI model is able to mimic the drop in EIR which derives merely from the lower ratio of vector to host in urban areas. In contrast with the other West African locations, urban transmission is overestimated in this location. In the second panel, it is seen that while both models are again similar and perform well in reproducing the observed CSPR rates, the VECTRI model does less well in reproducing the distinction between rural and urban environments. Although the CSPR is lower in urban environments, it is still far larger than the observations in VECTRI. An possible implication is that vector lifetimes for urban areas are too long in the model.

The seasonal cycle of EIR is shown in Figure 9 which demonstrates the onset, peak and consequential cessation of the season for the three model integrations, with symbols marking the same characteristics in observations. If transmission is assumed to be significant once the monthly EIR value exceeds 1, both models predict the timing of the onset, peak and cessation well for rural locations, although VECTRI maintains a very small background transmission rate for the two or three months prior to the onset. The higher interannual variability in the $\mathrm{LMM}_{2010}$ in the $E I R$ value of the peak month is apparent. In urban environments the season is shorter, with a slightly later onset. It is notable that in 1982, both models predict an earlier than usual onset for the malaria season, while they disagree on an anomalous outbreak predicted by VECTRI in 2004. In fact, while health facilities in endemic areas are usually well prepared to deal with the regular transmission season, such information concerning the potential for an earlier than usual onset could be very useful in a forecasting system. This is also clear from Figure 10, which shows the $P R$ annual cycle for rural location predicted by VECTRI. The box whiskers show the interannual variability, and it is seen that the greatest variability is in the onset phase of the malaria season. After the $P R$ saturates in the peak of the season the interannual variability is limited. Thus predictions of an early onset could provide some valuable information to health planners even in endemic regions allowing them to better prepare for anonymously early seasons.

\section{Regional integrations}

The strength of the VECTRI model is its ability to run on a regional scale at a relatively high horizontal resolution. The VECTRI integration made for Eastern Africa is compared to the MAP malaria analysis (Figure 11). As this is a single deterministic integration of the malaria model it is simply compared to the mean $P R$ of MAP, but future work will integrate the malaria model in a multi ensemble stochastic framework. This simple comparison of mean $P R$ distributions indicates that the model is able to reproduce the general patterns observed in the MAP analysis, with high rates in central and northeastern Uganda and Western Kenya, but dropping over the higher terrain, with the central Kenya, central Tanzania and most of Rwanda largely malaria-free $\left(E I R_{a}<0.01, P R<1 \%\right)$, as is the southwestern-most tip of Uganda.

The VECTRI model also reproduces the malaria zones in the warmer and more humid coastal regions in Kenya and Tanzania, but with values of $P R$ along the Kenyan coast and northern Tanzania in VECTRI (30-70\%) appear to greatly exceed those in the MAP analysis $(0-30 \%)$. This is a region in which the survey data incorporated into the MAP analysis is dense, although Figure Three of [113] still identifies this coastal region as relatively uncertain. A large part of the discrepancy between VECTRI and MAP is likely due to the increasing interventions including widespread distribution of insecticide-treated nets (ITNs) that have occurred over the past decade that have greatly decreased parasite ratios and hospital admissions $[117,118]$. For example, the survey of 30 villages in Malindi, Kilifi, and Kwale Districts carried out in the late 1990s before ITN distribution started [119] (included in the MAP analysis) reported a parasite prevalence ranging from 38 to $83 \%$, with a mean slightly exceeding $60 \%$ in each district, in close agreement with the VECTRI model. This highlights the importance of the future incorporations of interventions into VECTRI if it is to be applied to the seasonal forecasting task.

One key new component of the VECTRI model is the potential for water temperature of the surface hydrology model to impact larvae growth rates over regional scales, however, it was highlighted that the relationship was highly uncertain. To quantify this relative sensitivity to the temperature of water, a second set of high resolution (0.1 degree, equivalent to approximately $11 \mathrm{~km}$ ) regional simulations were repeated using a domain that covers both West and East Africa. The first uses the 

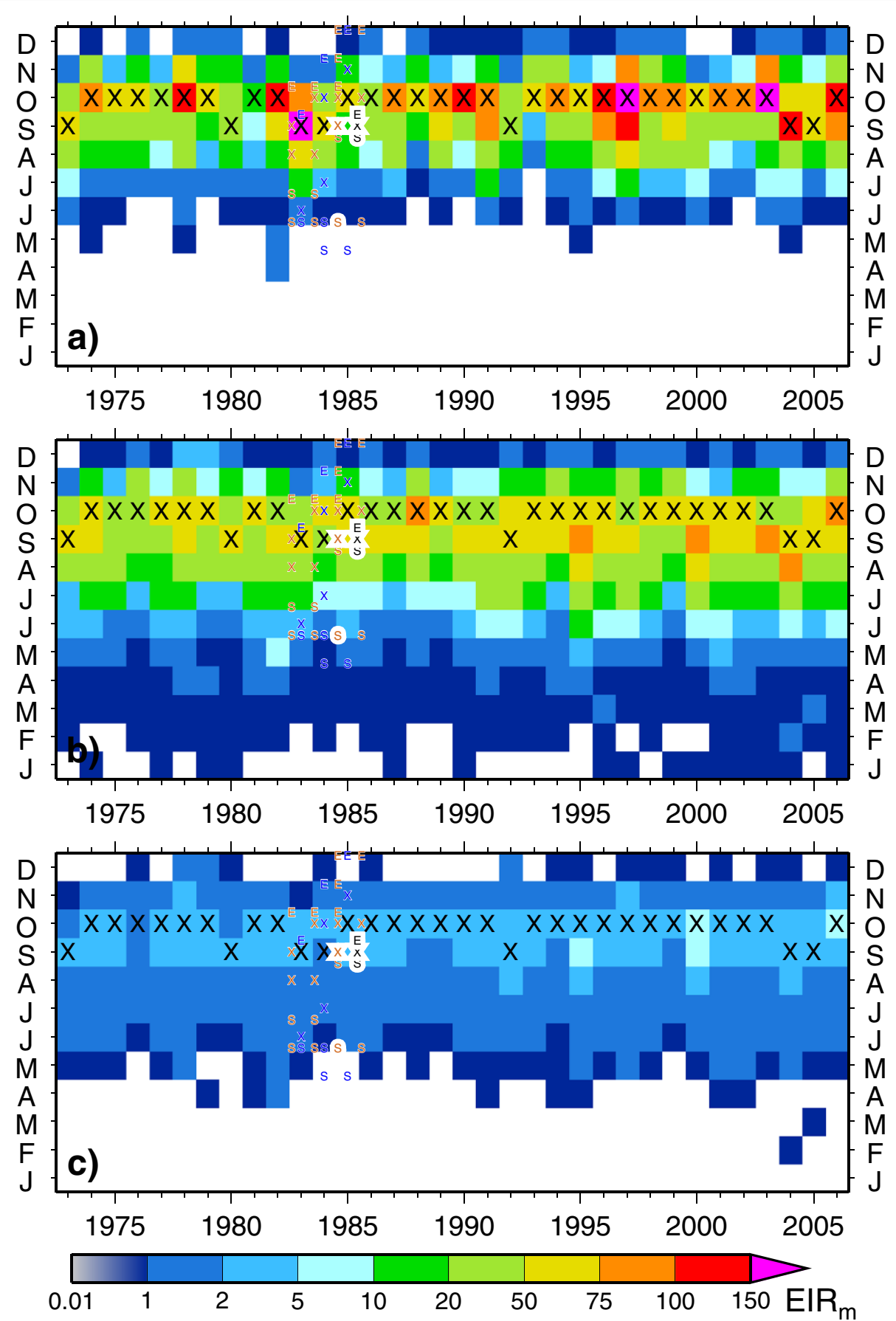

Figure 9 Seasonal transmission in Bobo-Dioulasso. Monthly mean EIR rates $\left(E I R_{m}\right)$ for $(\mathbf{a}) L_{M M} 2010$ (b) rural VECTRI (density $\left.32.2 \mathrm{~km}^{-2}\right)$ and $(\mathbf{c})$ urban VECTRI (density $1037 \mathrm{~km}^{-2}$ ). The large letter ' $X$ ' highlights the month in which the model produces a maximum in EIR. The start ('S'), peak ('X') and end ('E') months for transmission measured in various field campaigns are marked in smaller font. The rural observations (brown) are placed on the left of the square of a particular month, the irrigated observations (blue) in the middle and the urban observations (black) to the right.

default fixed larvae lifecycle lifespan of 12 days while the second uses the degree day parametrization with degree day of 90 days. The VECTRI output is compared to the MAP data using a joint probability function (Figure 12). There is agreement on where regions are malaria-free, and a positive correlation between the MAP data and the two VECTRI experiments. In both cases the VECTRI model appears to overestimate the $P R$ in locations where malaria exists compared to the MAP data, due to the lack of interventions and treatment in the VECTRI model. For 

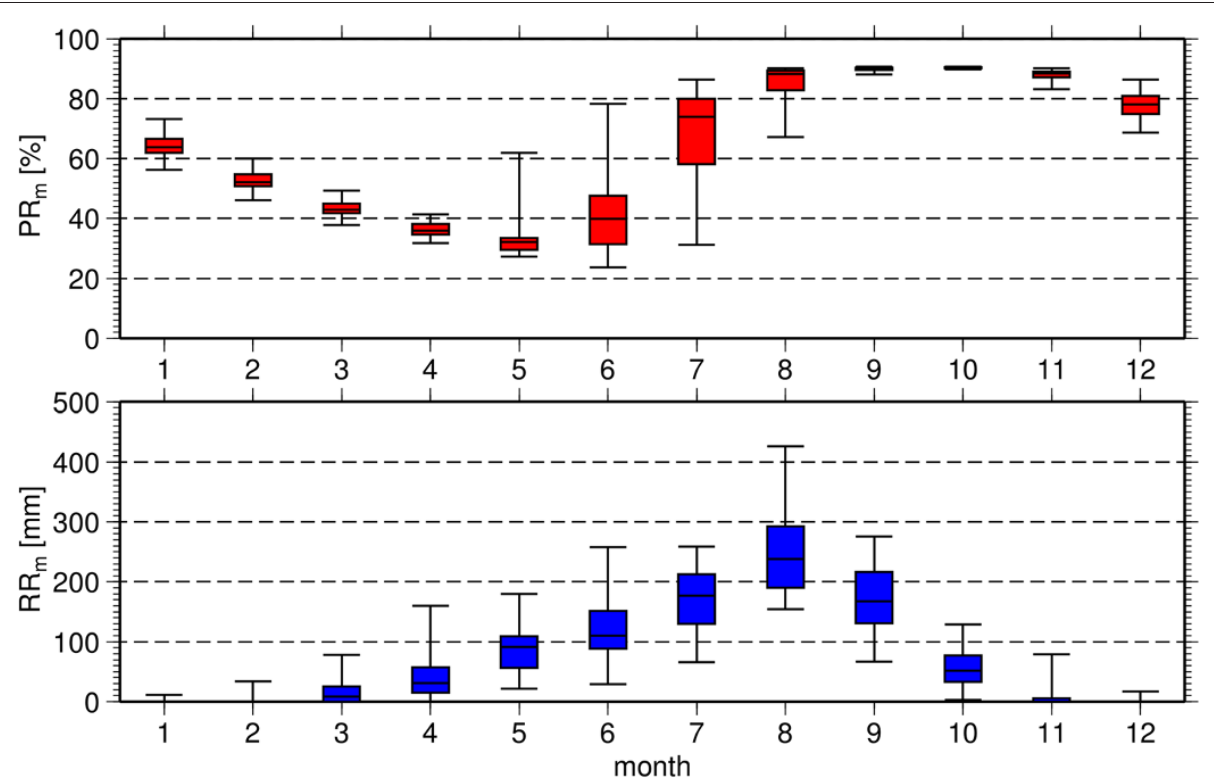

Figure 10 Annual cycle of $P \boldsymbol{R}$ in Bobo-Dioulasso. Annual cycle of monthly mean asexual parasite ratio ( $P R_{m}$; in \%) for a rural area near Bobo-Dioulasso from the 34 year simulation of VECTRI. The boxes mark the 25 and $75 \%$ quantiles while the whiskers give the minimum and maximum values.

example, the default clearance rate of 150 days is likely to be too long in endemic areas with widespread immunity. Moving from a constant larvae growth rate to a temperature sensitive growth rate sharpens the contrast in parasite loading between the lowlands and highlands, and this is seen in the disappearance of the intermediate values of $P R$ in the VECTRI simulation, with $P R$ either less than 0.1 or greater than 0.4 in these regions. This overestimation will likely improve once immunity and interventions are included in the model.

One of the new elements of the VECTRI model is the incorporation of the population density in the calculation of biting rates and subsequent transmission probabilities. The decreasing biting rate as population increases has been previously noted by [31-33], although the relationships vary due to contrasting methodologies of calculating $E I R$ and the differing locations of the studies. The sensitivity of EIR to population density in the deterministic East Africa integration (Figure 13) reveals a decreasing force of infection with increasing population. In Eastern Africa, the overall infectious biting rates are quite low in VECTRI, ranging from less than 1 year $^{-1}$ in city centres to around $80-100$ year $^{-1}$ in rural areas, which is to be expected as much of the highlands are malaria marginal or free. In contrast the VECTRI EIR rates for West Africa, are greater, exceeding 150 year $^{-1}$. The VECTRI West Africa domain excludes central Africa, for which still higher transmission rates are expected. The sensitivity of the EIR to population is comparable to the pan-continental field study summaries of [31], who reported a mean urban EIR of 7.1 year $^{-1}$ increasing to 167 year $^{-1}$ in rural areas. Likewise the analysis of 199 surveys by [33] reproduced in the figure lie in the range of the VECTRI simulations, although VECTRI appears to underestimate transmission at high population densities, relative to this particular study. Part of the reason for this could be the present neglect of population migration in VECTRI, which would tend to reduce the disparities between urban and rural EIR via its effect on $P R$. Other key parameters in the model could also be the cause. For example, as mentioned above, the malaria clearance rates set to 150 days neglect the potential acceleration of clearance with strong immunity. The slow clearance leads to $P R$ values that are either close to zero in malaria unsuitable zones, or between 0.4 and 0.9 in endemic zones. In addition, the survey data is subject to high uncertainty due to sampling, highlighted by the contrast between the results of $[31,33]$ for urban areas.

It is emphasized that these are single deterministic integrations of the VECTRI model using its default parameter settings, and an important next step will be to document how sensitive this relationship is to the parameter settings in a stochastic integration framework [18]. Nevertheless, Figure 13 includes the sensitivity to the parameter $\tau_{z o o}$, chosen as it is a tuned parameter in the model, with integrations using values of 35,70 and $100 \mathrm{~km}^{-2}$ also applied. As expected, these altered values impact the biting rate at low population densities, with lower values $\tau_{z o o}$ significantly increasing $E I R$ in sparsely populated areas. Above, 200 people per $\mathrm{km}^{-2}$ the parameter setting has no impact, and for all settings the model over-sensitivity 


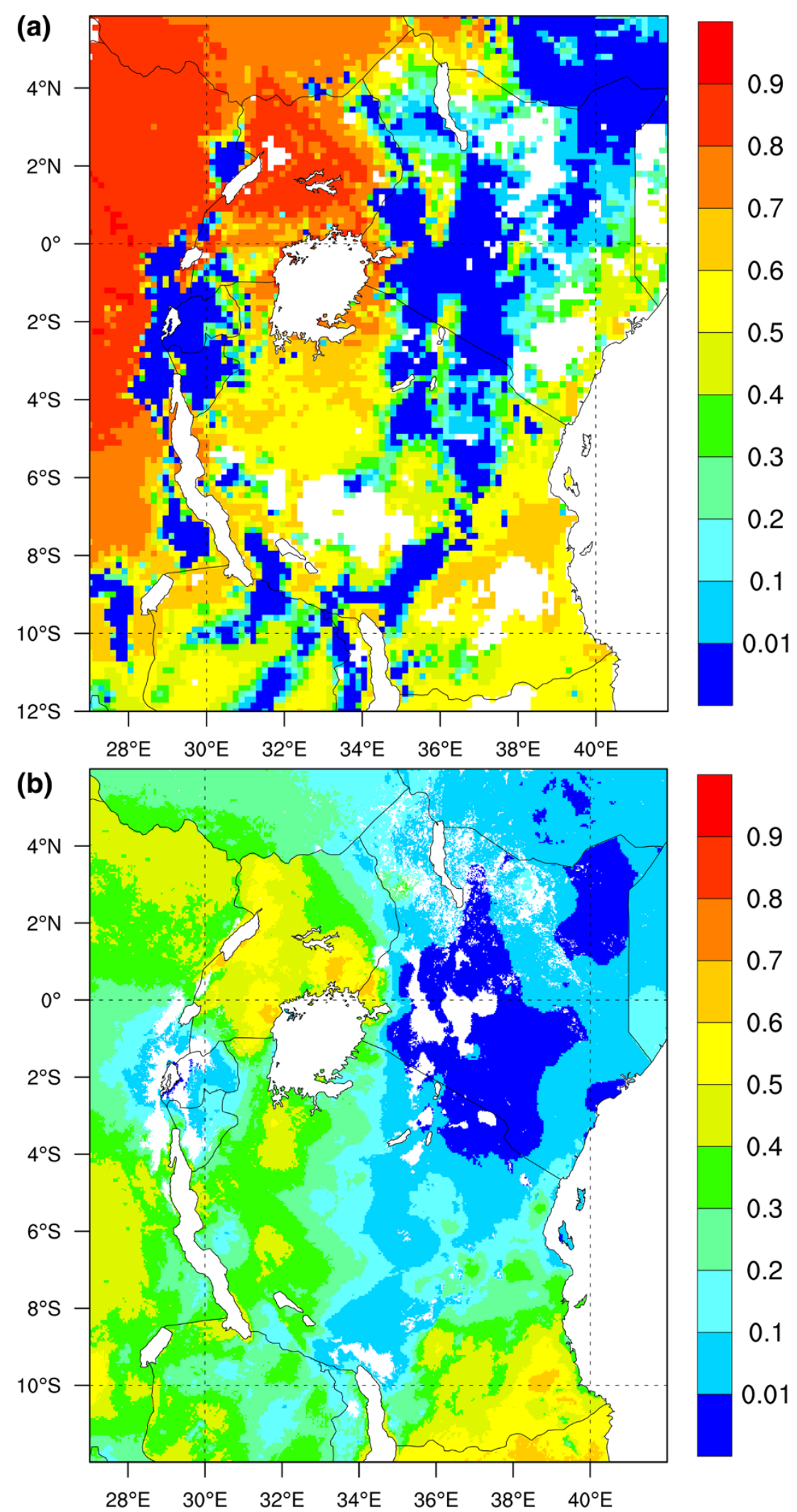

Figure 11 Regional simulation of $P R$ in Eastern Africa. Mean asexual parasite ratio ( $P R$; fraction) from (a) a 10 year-long VECTRI integration for East Africa and (b) MAP PR analysis. See text for details of model integration and data source. 

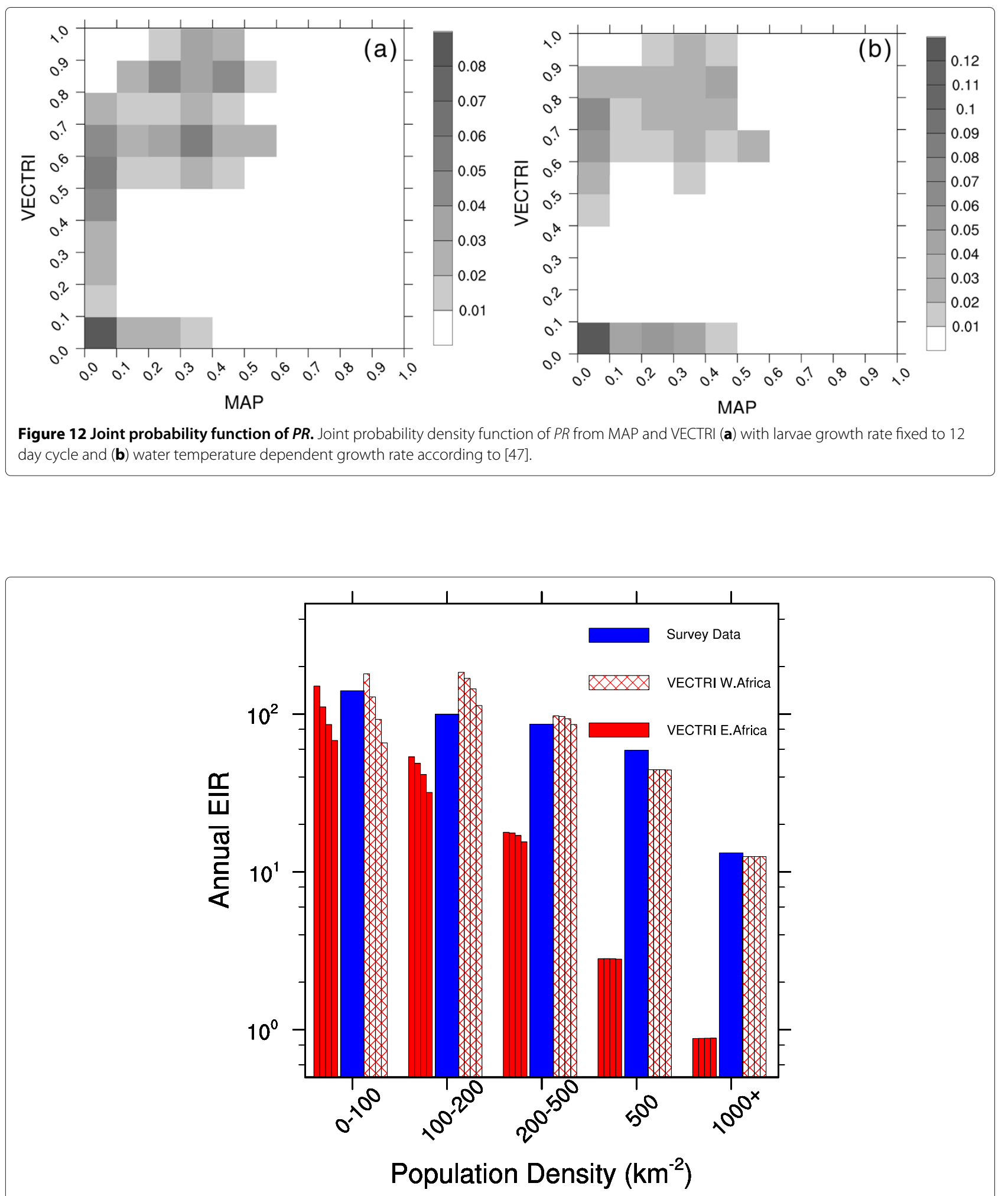

Figure 13 Sensitivity of EIR to population density. VECTRI modelled annual EIR as a function of population density divided into Western and Eastern zones of Africa, and the field survey data adapted from Figure Two of [33] (see their Figure One for survey locations). The VECTRI integrations were rerun with a range of values for $\tau_{z o 0}$, shown by the thin bars, representing values of 35,50 (default), 70 and $100 \mathrm{~km}^{-1}$ respectively from left to right. 
relative to [33] remains. This is because the parameter is designed to account for increasing zoophilicity at very low population densities, and thus are unable to represent the impact of human population movements which impact $P R$ at low and high population densities. Nevertheless, while the model presently neglects differences in surface hydrology in peri-urban versus rural areas [120], urban micro meteorology and housing differences [121], the result indicates that a zero order impact of population density is the dilution effect, where increasing population densities reduce the probability of parasite transmission to the vector $[31,122]$.

\section{Conclusions}

A new open source community model (contact the corresponding author) for malaria is presented that specifically represents dynamical equations for the relevant temperature sensitive cycles in the transmission of malaria, namely the larvae growth cycle in addition to the sporogonic and gonotrophic cycles. Each cycle is divided into an array of bins to resolve the respective processes in order to model the delay in the malaria season with respect to the driving cycle of rainfall, while temperature affects development rates. The VECTRI model implements a framework to consider the surface hydrology of temporary water bodies and ponds. It also incorporates the human/vector element by accounting for population density in the calculation of transmission probabilities, enabling the VECTRI model to differentiate between urban, peri-urban and rural environments and permitting the future incorporation of various interventions into the modelling framework in addition to a treatment of urban-rural and transnational migration.

The model has been integrated in an idealized equilibrium environment to compare the sensitivity of weather parameters to an existing dynamical model $\mathrm{LMM}_{2010}$, and the contrasting response to rainfall due to the incorporation of surface hydrology in VECTRI was noted. Two further sets of experiments confronted the model with a range of observational data for infectious biting rates and parasite ratios in the human population taken from several hundred field studies mostly based in West or Eastern Africa. The model reproduces mean rural infectious bite rates for a range of locations throughout West Africa quite well, with a seasonal cycle of $P R$ that appeared reasonable.

The incorporation of the population density in the biting rate calculation enables VECTRI to differentiate periurban and rural environments and it was demonstrated that the model was also able to reproduce the much lower $E I R$ and CSPR rates measured in a peri-urban suburb environment of Bobo-Dioulasso less than $20 \mathrm{~km}$ distant from a rural site with far higher transmission. This is interesting as it indicates that simply representing the lower ratio of vector to human numbers is sufficient to represent the lower transmission intensities generally found in periurban environments without invoking differences in surface hydrology, access to health facilities, housing quality or use of ITNs. Regional integrations for Eastern Africa highlighted this ability of VECTRI to grossly reproduce EIR rates as a function of population density, in addition to its reasonable distribution of endemic and malaria free regions, separated by intermediate altitude, epidemic regions, although relative to the MAP data, the VECTRI model tends to overestimate $P R$ in endemic zones. Whether this is due to missing processes, such as immunity or migration, or poor parameter choices remains unclear and the subject of investigation.

While already representing a useful tool to aid research into the understanding of malaria transmission, the VECTRI is undergoing further development to incorporate further aspects important for malaria transmission. These developments include: a flexible incorporation of various models for host immunity, a stochastic ensemble framework to account for uncertainty in model parameters and observations, improved surface hydrology that accounts for terrain slope, soil type and land use characteristics, a dynamical host model that includes migration, population demographics and urbanisation, explicit incorporation of commonly employed interventions, and lastly multiple vector types and vector dispersion.

\section{Competing interests}

The authors declare that they have no competing interests.

\section{Authors' contributions}

AMT designed and developed the VECTRI model, performed the VECTRI integrations and drafted the manuscript. VE advised on model

parameterization scheme choices in VECTRI, developed the West Africa station test suite and performed the LMM 2010 integrations for the model

intercomparison. Both authors read/approved and produced graphics for the final manuscript.

\section{Acknowledgements}

This work contributes towards two EU seventh framework projects: Quantifying Weather and Climate impacts on health in developing countries (QWeCl, grant 243964) and HEALTHY FUTURES (grant 266327). AMT received support from both projects, while VE was fully funded by QWeCl. Dr. Catherine Linard is thanked for providing an Africa-wide version of the Afripop dataset for use in the model, while the MAP team at Oxford University kindly provided original files of the MAP malaria analysis. Comments on the manuscript by Prof. David Taylor were appreciated, in addition to discussion with Profs. Mercedes Pascual and Andy Dobson at the ICTP workshop on infectious diseases in Arusha, Tanzania, 2012. The reviewers also gave suggestions that greatly improved the manuscript.

\section{Author details}

${ }^{1}$ Earth System Physics, Abdus Salam International Centre for Theoretical Physics (ICTP), Strada Costiera 11, Trieste, Italy. ${ }^{2}$ Institute of Geophysics and Meteorology, University of Cologne, Kerpener Str. 13, Cologne, Germany.

Received: 27 August 2012 Accepted: 17 January 2013

Published: 18 February 2013

\section{References}

1. McKenzie F: Why model malaria? Parasitol Today 2000, 16:511-516.

2. MacDonald G, Cuellar CB, Foll CV: The dynamics of malaria. Bull World Health Organ 1968, 38:743-755. 
3. Dietz K, Molineaux L, Thomas A: A malaria model tested in the African savannah. Bull World Health Organ 1974, 50:347-357.

4. Koella JC: On the use of mathematical models of malaria transmission. Acta Trop 1991, 49:1-25.

5. Thomson MC, Doblas-Reyes FJ, Mason SJ, Hagedorn R, Connor SJ, Phindela T, Morse AP, Palmer TN: Malaria early warnings based on seasonal climate forecasts from multi-model ensembles. Nature 2006, 439:576-579.

6. Ceccato P, Ghebremeskel T, Jaiteh M, Graves P, Levy M, Ghebreselassie S, Ogbamariam A, Barnston A, Bell M, Del Corral J, Connor SJ, Fesseha I, Brantly EP, Thomson MC: Malaria stratification, climate, and epidemic early warning in Eritrea. Am J Trop Med Hyg 2007, 77:61-68.

7. Lafferty KD: The ecology of climate change and infectious diseases. Ecol 2009, 90:888-900.

8. Ghebreyesus TA, Haile M, Witten KH, Getachew A, Yohannes M, Lindsay SW, Byass $P$ : Household risk factors for malaria among children in the Ethiopian highlands. Trans R Soc Trop Med Hyg 2000, 94:17-21.

9. ljumba JN, Mosha FW, Lindsay SW: Malaria transmission risk variations derived from different agricultural practices in an irrigated area of northern Tanzania. Med Vet Entomol 2002, 16:28-38.

10. Gething PW, Smith DL, Patil AP, Tatem AJ, Snow RW, Hay SI: Climate change and the global malaria recession. Nature 2010, 465:342-345.

11. Githeko AK, Ndegwa W: Predicting malaria epidemics in the Kenyan highlands using climate data: a tool for decision makers. Glob Chan Hum Health 2001, 2:54-63.

12. Ngom $R$, Siegmund A: Urban malaria in Africa: an environmental and socio-economic modelling approach for Yaoundé, Cameroon. Nat Hazards 2010, 55:599-619.

13. Lowe R, Bailey TC, Stephenson DB, Graham RJ, Coelho CAS, Sá Carvalho M, Barcellos C: Spatio-temporal modelling of climate-sensitive disease risk: Towards an early warning system for dengue in Brazil. Comput Geosci 2011, 37:371-381.

14. Paaijmans KP, Blanford S, Bell AS, Blanford JI, Read AF, Thomas MB: Influence of climate on malaria transmission depends on daily temperature variation. Proc Nat Acad Sci 2010, 107:15135-15139.

15. Hethcote HW: Qualitative analyses of communicable disease models. Math Biosci 1976, 28:335-356.

16. Ngwa GA, Shu WS: A mathematical model for endemic malaria with variable human and mosquito populations. Math Comput Model 2000, 32:747-763.

17. Pascual M, Cazelles B, Bouma MJ, Chaves LF, Koelle K: Shifting patterns: malaria dynamics and rainfall variability in an African highland. Proc R Soc Lond B Biol Sci 2008, 275:123-132.

18. Chitnis N, Hyman JM, Cushing JM: Determining important parameters in the spread of malaria through the sensitivity analysis of a mathematical model. Bull Math Biol 2008, 70:1272-1296.

19. Aron $J \mathrm{~L}$ : Mathematical modelling of immunity to malaria. Math Biosci 1988, 90:385-396.

20. Filipe JAN, Riley EM, Drakeley CJ, Sutherland CJ, Ghani AC: Determination of the processes driving the acquisition of immunity to malaria using a mathematical transmission model. PLoS Comput Biol 2007, 3:e255 doi:10.1371/journal.pcbi.0030255.

21. Doolan DL, Dobano C, Baird JK: Acquired immunity to malaria. Clin Microbiol Rev January 2009, 22(1):13-36.

22. Depinay JMO, Mbogo CM, Killeen G, Knols B, Beier J, Carlson J, Dushoff J, Billingsley P, Mwambi H, Githure J, Toure AM, McKenzie FE: A simulation model of African Anopheles ecology and population dynamics for the analysis of malaria transmission. Malar J 2004, 3: doi:10.1186/1475-2875-3-29.

23. Alonso D, Bouma M, Pascual M: Epidemic malaria and warmer temperatures in recent decades in an East African highland. Proc R Soc Lond B Biol Sci 2011, 278:1661-1669.

24. Jones AE, Morse AP: Application and validation of a seasonal ensemble prediction system using a dynamic malaria model. J Clim 2010, 23:4202-4215.

25. Jones AE, Morse AP: Skill of ENSEMBLES seasonal re-forecasts for malaria prediction in West Africa. Geophys Res Lett 2012, 39:L23707 doi:10.1029/2012GL054040.

26. Hoshen MB, Morse AP: A weather-driven model of malaria transmission. Malar J 2004, 3:32 doi:10.1029/2012GL054040.
27. Paaijmans KP, Wandago MO, Githeko AK, Takken W: Unexpected high losses of Anopheles gambiae larvae due to rainfall. PLOS ONE 2007, 2:e1146 doi:10.1371/journal.pone.0001146.

28. Dieng H, Rahman GMS, Abu Hassan A, Che Salmah MR, Satho T, Miake F, Boots $M$, Sazaly $A B$ : The effects of simulated rainfall on immature population dynamics of Aedes albopictus and female oviposition. Int J Biometeorol 2012, 56:113-120.

29. Ermert $V$, Fink $A H$, Jones $A E$, Morse AP: Development of a new version of the Liverpool Malaria Model. I. Refining the parameter settings and mathematical formulation of basic processes based on a literature review. Malar J 2011, 10: doi:10.1186/1475-2875-10-35.

30. Ermert V, Fink AH, Jones AE, Morse AP: Development of a new version of the Liverpool Malaria Model. II. Calibration and validation for West Africa. Malar J 2011, 10:62 doi:10.1186/1475-2875-10-62.

31. Robert V, Macintyre K, Keating J, McWilson W, Trappe JP, Duchemin JB, Beier JC: Malaria transmission in urban sub-Saharan Africa. Am J Trop Med Hyg 2003, 68:169-176.

32. Hay SI, Guerra CA, Tatem AJ, Atkinson PM, Snow RW: Urbanization, malaria transmission and disease burden in Africa. Nat Rev Microbiol 2005, 3:81-90.

33. Kelly-Hope L, McKenzie FE: The multiplicity of malaria transmission: a review of entomological inoculation rate measurements and methods across sub-Saharan Africa. Malar J 2009, 8:19 doi:10.1186/1475-2875-8-19.

34. Martens $\mathrm{P}$, Hall L: Malaria on the move: human population movement and malaria transmission. Emerg Infect Dis 2000, 6:103-109.

35. Stoddard ST, Morrison AC, Vazquez-Prokopec GM, Soldan VP, Kochel T, Kitron U, Elder JP, Scott TW: The role of human movement in the transmission of vector-borne pathogens. PLoS Neg/ Trop Dis 2009, 3:e481 doi:10.1371/journal.pntd.0000481

36. Tatem AJ, Smith DL: International population movements and regional Plasmodium falciparum malaria elimination strategies. Proc Nat Acad Sci 2010, 107:12222-12227.

37. Eckhoff PA: A malaria transmission-directed model of mosquito life cycle and ecology. Malar J 2011, 10:10 doi:10.1186/1475-2875-10-303.

38. Bomblies A, Duchemin JB, Eltahir EAB: Hydrology of malaria: Model development and application to a Sahelian village. Water Resour Res 2008, 44:W12445 doi:10.1029/2008WR006917.

39. Bomblies A, Duchemin JB, Eltahir EAB: A mechanistic approach for accurate simulation of village scale malaria transmission. Malar J 2009, 8:223 doi:10.1186/1475-2875-8-223.

40. Tiedtke M: A comprehensive mass flux scheme for cumulus parameterization in large-scale models. Mon Wea Rev 1989 117:1779-1800.

41. Tompkins AM: A prognostic parameterization for the subgrid-scale variability of water vapor and clouds in large-scale models and its use to diagnose cloud cover. J Atmos Sci 2002, 59:1917-1942.

42. Omumbo J, Platzer B, Girma A, Connor S J: Climate and health in, Africa: 10 years on - Workshop report. Tech. rep., International Research Institute for climate and society, IRI, 2011 available at [http://iri. columbia.edu/publications/download=1090]

43. Gillies MT: Studies on the dispersion and survival of Anopheles gambiae Giles in East Africa, by means of marking and release experiments. Bull Entomol Res 1961, 52:99-127.

44. Rowley WA, Graham CL: The effect of age on the flight performance of female Aedes aegypti mosquitoes. J Insect Physiol 1968, 14:719-728

45. Thomson MC, Connor SJ, Quinones ML, Jawara M, Todd J, Greenwood BM: Movement of Anopheles gambiae sI malaria vectors between villages in The Gambia. Med Vet Entomol 1995, 9:413-419.

46. Detinova TS: Age-grouping Methods in Diptera of Medical Importance with Special Reference to Some Vectors of Malaria. Monogr Ser World Health Organ 1962, 47:13-191.

47. Jepson WF, Moutia A, Courtois C: The malaria problem in Mauritius: The binomics of Mauritian anophelines. Bull Entomol Res 1947, 38:177-208.

48. Bayoh MN, Lindsay SW: Effect of temperature on the development of the aquatic stages of Anopheles gambiae sensu stricto (Diptera: Culicidae). Bull Entomol Res 2003, 93:375-381. 
49. Lyimo EO, Takken W, Koella JC: Effect of rearing temperature and larval density on larval survival, age at pupation and adult size of Anopheles gambiae. Entomol Exp App/ 1992, 63:265-271.

50. Kirby MJ, Lindsay SW: Effect of temperature and inter-specific competition on the development and survival of Anopheles gambiae sensu stricto and An. arabiensis larvae. Acta Trop 2009, 109:118-123.

51. Armstrong JA, Bransby-Williams WR: The maintenance of a colony of Anopheles gambiae, with observations on the effects of changes in temperature. Bull World Health Organ 1961, 24:427-435.

52. Martens WJM, Niessen LW, Rotmans J, Jetten TH, McMichael AJ: Potential impact of global climate change on malaria risk. Environ Health Perspect 1995, 103:458-464.

53. Thomson MC, Mason SJ, Phindela T, Connor SJ: Use of rainfall and sea surface temperature monitoring for malaria early warning in Botswana. Am J Trop Med Hyg 2005, 73:214-221.

54. Muirhead-Thomson RC: The ecology of vector snail habitats and mosquito breeding-places: The experimental approach to basic problems. Bull World Health Organ 1958, 19:637-659.

55. Le Menach A, Takala S, McKenzie FE, Perisse A, Harris A, Flahault A, Smith $\mathrm{DL}$ : An elaborated feeding cycle model for reductions in vectorial capacity of night-biting mosquitoes by insecticide-treated nets. Malar J 2007, 6:10 doi:10.1186/1475-2875-6-10.

56. Lyimo EO, Takken W: Effects of adult body size on fecundity and the pre-gravid rate of Anopheles gambiae females in Tanzania. Med Vet Entomol 1993, 7:328-332.

57. Hogg JC, Thompson MC, Hurd H: Comparative fecundity and associated factors for two sibling species of the Anopheles gambiae complex occuring sympatrically in The Gambia. Med Vet Entomol 1996, 10:385-391.

58. Takken W, Klowden MJ, Chambers GM: Effect of body size on host seeking and blood meal utilization in Anopheles gambiae sensu stricto (Diptera: Culicidae): the disadvantage of being small. J Med Entomol 1998, 35:639-645.

59. Smith DL, Dushoff J, Snow RW, Hay SI: The entomological inoculation rate and Plasmodium falciparum infection in African children. Nature 2005, 438:492-495.

60. Smith DL, McKenzie FE, Snow RW, Hay SI: Revisiting the basic reproductive number for malaria and its implications for malaria control. PLOS Biol 2007, 5:e42 doi:10.1371/journal.pbio.0050042.

61. Martens WJM, Jetten TH, Rottmans J, Niessen LW: Climate change and vector-borne diseases: A global modelling perspective. Glob Environ Change 1995, 5:195-209.

62. Martens WJM, Jetten TH, Focks DA: Sensitivity of malaria, schistomiasis and dengue to global warming. Clim Change 1997, 35:145-156.

63. Craig MH, Snow RW, le Sueur D: A climate-based distribution model of malaria transmission in sub-Saharan Africa. Parasitol Today 1999 15:105-111.

64. Linard C, Gilbert M, Snow RW, Noor AM, Tatem AJ: Population distribution, settlement patterns and accessibility across Africa in 2010. PLOS ONE 2012, 7:e31743 doi:10.1371/journal.pone.0031743.

65. Balk DL, Deichmann U, Yetman G, Pozzi F, Hay SI, Nelson A: Determining global population distribution: methods, applications and data. Adv Parasitol 2006, 62:119-156.

66. Dekker T, Steib B, Carde RT, Geier M: L-lactic acid: a human-signifying host cue for the anthropophilic mosquito Anopheles gambiae. Med Vet Entomol 2002, 16:91-98.

67. Mahande A, Mosha F, Mahande J, Kweka E: Feeding and resting behaviour of malaria vector, Anopheles arabiensis with reference to zooprophylaxis. Malar J 2007, 6:100 doi:10.1186/1475-2875-6-100.

68. Killeen GF, McKenzie FE, Foy BD, Bøgh C, Beier JC: The availability of potential hosts as a determinant of feeding behaviours and malaria transmission by African mosquito populations. Trans $R$ SoC Trop Med Hyg 2001, 95:469-476.

69. Bøgh C, Clarke SE, Pinder M, Sanyang F, Lindsay SW: Effect of passive zooprophylaxis on malaria transmission in The Gambia. J Med Entomol 2001, 38:822-828.

70. Koella JC, SÖrensen FL, Anderson RA: The malaria parasite, Plasmodium falciparum, increases the frequency of multiple feeding of its mosquito vector, Anopheles gambiae. Proc R Soc Lond B Biol Sci 1998, 265:763-768.
71. Dye C, Hasibeder G: Population dynamics of mosquito-borne disease: effects of flies which bite some people more frequently than others. Trans R Soc Trop Med Hyg 1986, 80:69-77.

72. Knols BGJ, de Jong R, Takken W: Differential attractiveness of isolated humans to mosquitoes in Tanzania. Trans R Soc Trop Med Hyg 1995, 89:604-606

73. Mukabana WR, Takken W, Coe R, Knols BGJ: Host-specific cues cause differential attractiveness of Kenyan men to the African malaria vector Anopheles gambiae. Malar J 2002, 1:17 doi:10.1186/1475-2875-1-17.

74. Rickman LS, Jones TR, Long GW, Paparello S, Schneider I, Paul CF, Beaudoin RL, Hoffman SL: Plasmodium falciparum-infected Anopheles stephensi inconsistently transmit malaria to humans. Am J Trop Med Hyg 1990, 43:441-445.

75. Beier JC, Oster CN, Onyango FK, Bales JD, Sherwood JA, Perkins PV, Chumo DK, Koech DV, Whitmire RE, Roberts CR, Diggs CL, Hoffman SL: Plasmodium falciparum incidence relative to entomologic inoculation rates at a site proposed for testing malaria vaccines in western Kenya. Am J Trop Med Hyg 1994, 50:529-536.

76. Shute $\mathrm{PG}$, Maryon M: A study of gametocytes in a West African strain of Plasmodium falciparum. Trans R Soc Trop Med Hyg 1951, 44:421-438

77. Miller MJ: Observations on the natural history of malaria in the semi-resistant West African. Trans R Soc Trop Med Hyg 1958, 52:152-168.

78. Hawking F, Wilson ME, Gammage K: Evidence for cyclic development and short-lived maturity in the gametocytes of Plasmodium falciparum. Trans R Soc Trop Med Hyg 1971, 65:549-555.

79. Day KP, Hayward RE, Dyer M: The biology of Plasmodium falciparum transmission stages. Parasitol 1998, 116(Suppl):S95-S109.

80. Le Prince JA: Mosquito control in relation to impounded water supply. J Am Water Works Assoc 1927, 17:31-36.

81. Fillinger U, Sombroek H, Majambere S, Van Loon E, Takken W, Lindsay SW: Identifying the most productive breeding sites for malaria mosquitoes in The Gambia. Malaria Journal 2009, 8:62 doi:10.1186/1475-2875-8-62.

82. Haque U, Hashizume M, Glass GE, Dewan AM, Overgaard HJ, Yamamoto T: The role of climate variability in the spread of malaria in Bangladeshi highlands. PLOS ONE 2010, 5:e14341 doi:10.1371/journal.pone.0014341.

83. Desconnets JC, Taupin J, Lebel T, Leduc C: Hydrology of the HAPEX-Sahel Central Super-Site: surface water drainage and aquifer recharge through the pool systems. J Hydrol 1997, 188:155-178.

84. Gianotti RL, Bomblies A, Eltahir EAB: Hydrologic modeling to screen potential environmental management methods for malaria vector control in Niger. Water Resour Res 2009, 45:W08438 doi:10.1029/2008WR007567.

85. Martin-Rosales W, Leduc C: Dynamiques de vidange d'une mare temporaire au Sahel: I'exemple de Banizoumbou (Sud-Ouest du Niger). Comptes Rendus Geoscience 2003, 335(5):461-468.

86. Hayashi M, Kamp Van der G: Simple equations to represent the volume-area-depth relations of shallow wetlands in small topographic depressions. J Hydrol 2000, 237:74-85.

87. Brooks RT, Hayashi M: Depth-area-volume and hydroperiod relationships of ephemeral (vernal) forest pools in southern New England. Wetlands 2002, 22(2):247-255.

88. Soti V, Puech C, Lo Seen D, Bertran A, Vignolles C, Mondet B, Dessay N, Tran A: The potential for remote sensing and hydrologic modelling to assess the spatio-temporal dynamics of ponds in the Ferlo Region (Senegal). Hydrol Earth Sys Sci Discuss 2010, 14:1449-1464.

89. Wanjala CL, Githeko AK, Waitumbi JN: Assessing the impact of topography on malaria exposure and malaria epidemic sensitivity in the Western Kenya highlands. Malar J 2010, 9(Suppl 2):P59 doi:10.1186/1475-2875-9-S2-P59.

90. Gimnig JE, Ombok M, Otieno S, Kaufman MG, Vulule JM, Walker ED: Density-dependent development of Anopheles gambiae (Diptera: Culicidae) larvae in artificial habitats. J Med Entomo/ 2002, 39:162-172.

91. Munga S, Minakawa N, Zhou G, Barrack OOJ, Githeko AK, Yan G: Effects of larval competitors and predators on oviposition site selection of Anopheles gambiae sensu stricto. J Med Entomo/ 2006, 43:221-224. 
92. Paaijmans KP, Jacobs AFG, Takken W, Heusinkveld BG, Githeko AK, Dicke $M$, Holtslag AAM: Observations and model estimates of diurnal water temperature dynamics in mosquito breeding sites in western Kenya. Hydrol Process 2008, 22:4789-4801.

93. Paaijmans KP, Takken W, Githeko AK, Jacobs AFG: The effect of water turbidity on the near-surface water temperature of larval habitats of the malaria mosquito Anopheles gambiae. Int J Biometeorol 2008 52:747-753.

94. Jacobs AFG, Heusinkveld BG, Kraai A, Paaijmans KP: Diurnal temperature fluctuations in an artificial small shallow water body. Int J Biometeorol 2008, 52:271-280.

95. Paaijmans KP, Heusinkveld BG, Jacobs AFG: A simplified model to predict diurnal water temperature dynamics in a shallow tropical water pool. Int J Biometeorol 2008, 52:797-803.

96. Ermert V: Risk assessment with regard to the occurrence of malaria in Africa under the influence of observed and projected climate change. PhD thesis. Cologne, Germany: University of Cologne; 2010. Available online at [http://kups.ub.uni-koeln.de/3109/]

97. Carnevale $P$, Robert $V$ : Introduction of irrigation in Burkina Faso and its effect on malaria transmission. In Effects of Agricultural Development on Vector-borne Diseases. Edited by FAO. Rome: FAO; 1987:57-67.

98. Lochouarn L, Gazin I: La transmission du paludisme dans la ville de Bobo-Dioulasso (Burkina Faso). Ann Soc Belg Med Trop 1993, 73:287-296.

99. Robert V, Gazin P, Boudin C, Molez JF, Oueddraogo V, Carnevale P: La transmission du paludisme en zone de savane arboreé et en zone rizicole des Bobo-Dioulasso (Burkina Faso). Ann Soc Belg Med Trop 1985, 65:201-214.

100. Robert $V$, Gazin $P$, Benasseni $R$, Carnevale $P$ : Le paludisme urbain à Bobo-Dioulasso (Burkina Faso). In Urbanisation et santé dans le Tiers Monde: transition épidémiologique, changement social et soins de santé primaires. Edited by Salem G, Emile J. Paris: ORSTROM; 1989:181-185.

101. Gazin $P$, Goncalves K, Koné B, Lochouam L: Incidence des accès palustres dans un quartier de la ville de Bobo-Dioulasso (Burkina Faso). Bull Soc Pathol Exot 1996, 89:200-203.

102. Robert V, Gazin P, Boudin C, Molez JF, Oueddraogo V, Carnevale P: La transmission du paludisme en zone de savane arboreé et en zone rizicole des Bobo-Dioulasso (Burkina Faso). Ann Soc Belg Med Trop 1985, 65:201-214.

103. Boudin C, Robert V, Carnevale P, Ambroise TP: Epidemiology of Plasmodium falciparum in a rice field and a savanna area in Burkina Faso: seasonal fluctuations of gametocytaemia and malaria infectivity. Ann Trop Med Parasitol 1991, 85:377-385.

104. Boudin C, Robert V, Carnevale P, Ambroise-Thomas P: Epidemiology of Plasmodium falciparum in a rice field and a savanna area in Burkina Faso. Comparative study on the acquired immunoprotection in native populations. Acta Trop 1992, 51:103-111.

105. Boudin C, Robert V, Verhave JP, Carnevale P, Ambroise-Thomas P: Plasmodium falciparum and $P$. malariae epidemiology in a West African village. Bull World Health Organ 1991, 69:199-205.

106. Robert V, Carnevale P: Influence of deltamethrin treatment of bed nets on malaria transmission in the Kou valley, Burkina Faso. Bull World Health Organ 1991, 69:735-740.

107. Love $\mathrm{T}$ : The climate prediction center rainfall algorithm version 2 . Tech. rep., NOAA Climate Prediction Center, 2002. available at [http://www.cpc.noaa.gov/products/fews/]

108. Dee DP, Uppala SM, Simmons AJ, Berrisford P, Poli P, Kobayashi S, Andrae U, Balmaseda MA, Balsamo G, Bauer P coauthors: The ERA-Interim reanalysis: configuration and performance of the data assimilation system. Q J R Meteoro/ Soc 2011, 137(656):553-597.

109. Giorgi F, Francisco R, Pal J, Effects of a subgrid-scale topography and land use scheme on the simulation of surface climate and hydrology. Part I: Effects of temperature and water vapor disaggregation. J Hydrometeor 2003, 4:317-333.

110. Smith WHF, Sandwell DT: Global sea floor topography from satellite altimetry and ship depth soundings. Science 1997, 277(5334):1956-1962.

111. Hay SI, Snow RW: The malaria atlas project: developing global maps of malaria risk. PLoS Med 2006, 3:e473 doi:10.1371/journal.pmed.0030473.
112. Hay SI, Guerra CA, Gething PW, Patil AP, Tatem AJ, Noor AM, Kabaria CW, Manh BH, Elyazar IRF, Brooker SJ, Smith DL, Moyeed RA, Snow RW: A world malaria map Plasmodium falciparum endemicity in 2007. PLoS Med 2009, 6:e1000048 doi:10.1371/journal.pmed.1000048.

113. Gething PW, Patil AP, Smith DL, Guerra CA, Elyazar IRF, Johnston GL, Tatem AJ, Hay SI: A new world malaria map: Plasmodium falciparum endemicity in 2010. Malar J 2011, 10:378 doi:10.1186/1475-2875-10-378

114. Patil AP, Gething PW, Piel FB, Hay SI: Bayesian geostatistics in health cartography: the perspective of malaria. Trends Parasito/ 2011, 27:246-253.

115. Ermert V, Fink AH, Morse AP, Paeth H: Environ Health Perspect. 2012, 120:77-84

116. Thomson RC: The reactions of mosquitoes to temperature and humidity. Bull Entomol Res 1938, 29:125-140.

117. Okiro EA, Hay SI, Gikandi PW, Sharif SK, Noor AM, Peshu N, Marsh K, Snow RW: The decline in paediatric malaria admissions on the coast of Kenya. Malar J 2007, 6:151 doi:10.1186/1475-2875-11-2.

118. O'Meara WP, Bejon P, Mwangi TW, Okiro EA, Peshu N, Snow RW, Newton CRJC, Marsh K: Effect of a fall in malaria transmission on morbidity and mortality in Kilifi, Kenya. J Lancet 2008 372:1555-1562.

119. Mbogo CM, Mwangangi JM, Nzovu J, Gu W, Yan G, Gunter JT, Swalm C, Keating J, Regens JL, Shililu JI, Githure JI, Beier JC: Spatial and temporal heterogeneity of Anopheles mosquitoes and Plasmodium falciparum transmission along the Kenyan coast. Am J Trop Med Hyg 2003, 68:734-742.

120. Dongus S, Nyika D, Kannady K, Mtasiwa D, Mshinda H, Gosoniu L, Drescher A, Fillinger U, Tanner M, Killeen G, Castro MC: Urban agriculture and Anopheles habitats in Dar es Salaam, Tanzania. Geospat Health 2009, 3:189-210.

121. Atieli H, Menya D, Githeko A, Scott T: House design modifications reduce indoor resting malaria vector densities in rice irrigation scheme area in western Kenya. Malar J 2009, 8:108 doi:10.1186/1475-2875-8-108

122. Manga L, Fondjo E, Carnevale $P$, Robert V: Importance of low dispersion of Anopheles gambiae (Diptera: Culicidae) on malaria transmission in hilly towns in south Cameroon. J Med Entomol 1993, 30:936-938

\section{doi:10.1186/1475-2875-12-65}

Cite this article as: Tompkins and Ermert: A regional-scale, high resolution dynamical malaria model that accounts for population density, climate and surface hydrology. Malaria Journal 2013 12:65.

\section{Submit your next manuscript to BioMed Central} and take full advantage of:

- Convenient online submission

- Thorough peer review

- No space constraints or color figure charges

- Immediate publication on acceptance

- Inclusion in PubMed, CAS, Scopus and Google Scholar

- Research which is freely available for redistribution

Submit your manuscript at www.biomedcentral.com/submit
C Biomed Centra 